IUSEAU OF STANGARDS

\title{
$00 \mathrm{~T}=31980$ \\ LIBRARY
}

U. S. DEPARTMENT OF COMMERCE BUREAU OF STANDARDS

WASHING, CLEANING, AND POLISHING MATERIALS

CIRCULAR OF THE BUREAU OF STANDARDS, No. 383 



\section{U. S. DEPARTMENT OF COMMERCE \\ R. P. LAMONT, Secretary \\ BUREAU OF STANDARDS \\ GEORGE K. BURGESS, Director}

CIRCULAR OF THE BUREAU OF STANDARDS, №. 383

[Supersedes Circular No. 62, third edition]

\section{WASHING, CLEANING, AND POLISHING MATERIALS}

ISSUED, SEPTEMBER 10, 1930

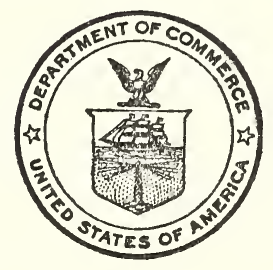

UNITED STATES

GOVERNMENT PRINTING OFFICE

WASHINGTON : 1930 



\section{WASHING, CLEANING, AND POLISHING MATERIALS}

\section{ABSTRACT}

This publication discusses briefly the use of water in laundering, pointing out the effects of impurities in water and means for their elimination. A brief description of the general composition of soap, soap-manufacturing processes, and the common varieties of soap products is followed by a short discussion of alkaline cleansers and miscellaneous detergent or laundry aids, such as bleaches, sours, bluing, and starch. Brief discussions are also included on dry-cleaning operations, solvents, dry-cleaning soaps, stain removal, finishing, reclamation of solvent, and elimination of static electricity in dry-cleaning plants. Sections are devoted to furniture and automobile polishes, metal polish, floor wax and polish, polishing cloths, dust cloths, sweeping compounds, and wall-paper cleaner. A list of the Government specifications for the products covered, numerous references, and suggested formulas for some items are also given. Recommended specifications are given in the appendixes for two grades of laundry soap.

\section{CONTENTS}

I. Introduction

II. Soap solutions and cleansing action

III. Water

1. Impurities

2. Hardness

(a) Temporary hardness

(b) Permanent hardness

3. Water in laundering

4. Water softening

IV. Soap. Dissolved impurities other than hardness

1. General composition of soap. Methods of manufacture
eties of soap

1. General composition of soap
V. Varieties of soap of manufacture

1. Toilet soaps

(a) Milled toilet soaps

(b) Floating soaps...

(c) Castile soap

(d) Transparent soaps

(e) Liquid toilet soaps

(f) Shaving soaps.

(g) Tar soaps

(h) Hand grit soaps

2. Salt-water or marine soap.

3. Laundry or common soaps

(a) Laundry cake or bar soap......

(b) Chip soaps and powered soaps.

5. Soap powders

5. Scouring powders 6

7. Soft soaps

8. Miscellaneous soaps

(a) Liquid laundry soaps

(b) Mottled or marbled soaps.

(c) Hand soaps for use without water....

(d) Hard-water soaps.

VI. Alkaline cleansers 18

2. "Powdered ammonia", 18

3. Borax

4. Soda ash...... 19 
VI. Alkaline cleansers-Continued.

5. Laundry soda (washing soda)

6. Sal soda ("washing crystals" or "soda crystals")

7. Monohydrate crystals or granular sodium carbonate.--

8. Caustic soda (lye), (drain pipe cleaner) ......

9. "Special alkalies"'

10. Trisodium phosphate.

11. Sodium silicate.

12. "Colloidal cleanlng powders",

13. Potassium compounds

VII. Miscellaneous detergent aids

1. Bleaching agents.

2. Sours

3. Bluings

4. Laundry starch

5. References_.

VIII. Dry cleaning

1. Nature and application of dry cleaning

2. Dry-cleaning solvents

3. Dry-cleaning soaps

4. The dry-cleaning process

(a) Method for cleaning heavy woolens.......

(b) Method for cleaning fancy wool, silk, and rayon_-

(c) Method for cleaning cotton and linen.........

5. Stain removal or "spotting"

6. Finishing

7. Reclamation of dry-cleaning solvent.

(a) Distillation process

(b) Alkali-carbon process.

(c) Alkali-continuous process

(d) Acid base - continuous process

(e) Filitration

(f) Processes using special reagents....

8. Elimination of static electricity

IX. Polishes References

1. Furniture and automobile polish

(a) Oil polishes

(c) Special mixtures.

(d) Formulas

2. Metal polish

3. Floor polish

4. Glass polish

5. Stove polish

6. Shoe polish

7. Polishing cloth.

8. Dust cloth, oiled

9. References

$\mathrm{X}$. Sweeping compounds

1. References.

XI. Wall-paper cleaner

XII. Specifications.

1. References.

Appendix 1. Proposed specification for special grade laundry soap

1. General

2. Sampling

3. Laboratory examination.

4. Reagents.

Appendix 2. Proposed specification for hard water grade laundry soap
1. General
2. Sampling
3. Laboratory examination.
4. Reagents. 


\section{INTRODUCTION}

To answer many mail inquiries from the public, the National Bureau of Standards has issued numerous circulars on special topics. One of these circulars (Circular No. 62 on Soap) has been expanded and is now issued under the more comprehensive title, "Washing, Cleaning, and Polishing Materials." It is designed to give information in a concise and popular form.

In addition to the references listed, valuable assistance in preparing this circular has been received from $T$. R. Lockwood and R. W. Mitchell, of the Lockwood Brackett Co.; G. H. Johnson, director of research, Laundryowners' National Association; L. E. Young, of the Cincinnati Soap Co.; Archibald Campbell, formerly vice president of the Globe Soap Co.; F. W. Blair and associates of the Procter \& Gamble Co.; C. C. Hubbard, formerly director of education; W. K. Cooley, principal, National Association Institute of Dyeing and Cleaning (Inc.); (National Association of Dyers and Cleaners); and P. H. Walker, W. E. Emley, and other members of the bureau's staif.

\section{SOAP SOLUTIONS AND CLEANSING ACTION}

Although many theories have been put forward to explain the detergent or cleansing action of soap solutions, the question may be considered as still unsettled. The following brief discussion is intended to explain in part some of the properties of soap solutions as used in laundering processes.

Dirt can be removed if a film of liquid can be forced between it and the fabric or other material. Obviously, the ability of the solution to readily wet the fabric, and the foreign matter is of major importance. Drops of pure water assume a spherical shape and are slowly absorbed by fabrics; the surface of the water acts as if it consisted of an extremely thin elastic skin. The force which causes a volume of liquid to take a form with the least surface area (a globe or sphere) is known as surface tension. Solutions of low-surface tension will wet surfaces with which they come in contact more readily than will solutions of high-surface tension. Soap is the most effective agent for lowering the surface tension (breaking or weakening the surface skin) of water, and so increasing the wetting power of the solution.

When a fatty oil and water are shaken together, the oil is distributed through the water in the form of small drops; after standing, the oil and water rapidly separate into two distinct layers. When the water is replaced by a soap solution the oil is distributed or dispersed throughout the solution in the form of a fine suspension; the "milky" solution is known as an emulsion. In the latter case the drops of oil are so small that it takes them a long time to coalesce to larger drops and separate out. The property of soap solutions and alkaline solutions to produce emulsions with oils or fats is known as emulsification and is one of the properties which enable them to remove grease and oil.

On adding soluble soap or solutions of soap to a hard water, the calcium, magnesium, iron, or other elements that cause hardness in water will react with the soap to form insoluble soaps. The use of hard water not only wastes soap, but may cause very poor laundry 
work by the deposition of these insoluble soaps on the fabrics. "Soft water" is simply water that is free from the substances that produce insoluble soap compounds, and water softening consists in removing these materials from the water, usually as finely divided insoluble compounds.

No satisfactory test has been devised for measuring the detergent power of a soap and, therefore, large users of soap buy such products on specifications based on chemical analysis.

The process of washing consists essentially of the following three stages: (1) Wetting the fabric and the dirt; (2) removing the dirt from the fabric; and (3) retaining the removed dirt in suspension in the solution and preventing it from redepositing on the fabric, particularly when the solution is diluted by rinse water.

In the dry-cleaning process the fabrics are immersed in a fluid other than water. In this process the wetting and solvent power of the dry-cleaning solvent, action of dry-cleaning soaps, and mechanical agitation are the main factors. In general, the cleansing action of the solvent and other detergents is, in part at least, similar to that outlined above.

\section{WATER}

\section{IMPURITIES}

First in importance and volume used in the so-called wet washing operations is water. All natural waters contain impurities, which for convenience may be divided into two classes-suspended and dissolved impurities. The suspended matter (clay, etc.) that will affect washing operations can be removed by proper filtration and sedimentation. The dissolved impurities may be divided into two groups-(1) those causing hardness, and (2) impurities that do not cause hardness.

\section{HARDNESS}

Hardness is often expressed in degrees or grains per United States gallon, calculated as calcium carbonate $\left(\mathrm{CaCO}_{3}\right)$; that is, $1^{\circ}$ of hardness indicates the presence of calcium and magnesium compounds (and other soap-destroying compounds) in an amount equivalent to 1 grain of calcium carbonate $\left(\mathrm{CaCO}_{3}\right)$ per United States gallon. Hardness is now more often expressed as parts per million of the above compounds, calculated to calcium carbonate. (One grain per United States gallon $=17.14$ parts per $1,000,000$.) Hardness is of two kinds, as follows:

(a) Temporary Hardness.- - Hardness, due to the bicarbonates of calcium and magnesium, is known as temporary or carbonate hardness. Other elements, such as iron, aluminum, strontium, or barium, would cause hardness, but these are not found in the water of public supplies in quantities large enough to have any appreciable effect. Temporary hardness may be removed from water by the simple process of boiling, carbon dioxide being expelled and the normal carbonates of the elements which cause "hardness" being precipitated. Temporary hardness may also be removed by the addition of limewater or slaked lime, but the boiling method is preferable in the household. The chemicals generally used in household washing to reduce or remove hardness are trisodium phosphate, sodium carbonate (soda ash), washing soda (laundry soda), borax, and ammonia. 
One or more of the first four of these or sodium silicate is frequently incorporated as a "builder" in soaps to act as water softeners and detergent aids.

(b) Permanent Hardness.-Hardness due to all other compounds of calcium and magnesium, generally sulphates, chlorides, and nitrates is known as permanent or noncarbonate hardness. Permanent hardness is not affected by mere boiling, but can be removed from water either by chemical treatment or by distillation.

\section{WATER IN LAUNDERING}

It is obvious that only soft water, free from iron, suspended matter, and oil should be used in laundering operations. Calcium, magnesium, iron, and other heavy metals not only render a portion of the soap ineffective as a detergent but form additional material to be emulsified by the remaining soluble alkali metal soap (soda or potash soap). Some of the insoluble calcium and magnesium soaps will be deposited in the fabric and may not be completely eliminated in the suds bath. In the rinsing bath most of the insoluble soap, together with some of the suspended dirt, may be deposited on the fabric. When precipitated uniformly on fabrics this produces gray, dingy work, or "grayness" that is not corrected by bleaching. When deposited in spots or globules it produces the so-called soap specks or grease specks. Iron causes yellowed work. This may be corrected by the use of oxalic acid or other iron solvent, followed by thorough rinsing with water to remove all traces of the reagent used, but the proper piocedure is to remove the iron compounds from the water before use. Sulphides in water may cause stains, especially with iron. When the use of a sulphide water can not be avoided, it should be treated with an oxidizing agent, such as "hypochlorite bleach," to convert the sulphides into sulphates, and should be kept alkaline in every operation prior to souring and rinsing.

The value of softened water is indicated in the studies made by H. B. Robbins, H. J. MacMillan, and L. W. Bosart ${ }^{1}$ who found that about 10.4 ounces of soap is required to soften 100 gallons of water of 77.1 parts per $1,000,000$ of hardness and 30.4 ounces of soap if the hardness is 238.2 parts per $1,000,000$.

In addition to the efiects noted above, the compounds which cause hardness also cause the scale which deposits in boilers and pipes. On the other hand, soft waters are generally more corrosive than hard waters and are more likely to cause corrosion or pitting and leaks in steam and water pipes. T'he rusting of iron or steel piping, especially hot water lines, is often manifested in the red color that appears in water. This color is due to finely divided hydrated iron oxide. This so-called red water has caused some power laundries much concern. The researches of Russell ${ }^{2}$ and his colleagues have resulted in the development of a commercial process for the elimination of this trouble by the use of sodium silicate to form protective films in the pipes.

The United States Geological Survey ${ }^{3}$ has classified the public water supplies of the country according to hardness, as follows: (a) From 0 to 55 parts per 1,000,000, soft. "In ordinary household

1 Ind. Eng. Chem., 18, pp. 27-29; 1926.

2 Russell, R. P., Pust Prevention in Laundries, Starchroom Laundry Jo.; Dec. 15, 1923. Speller, F. N., Corrosion-Causés and Prevention, McGraw-Hill Book Co. (Inc.), New York, N. Y.

'Collins, W. D., The Industrial Utility of Public Water Supplies, U. S. Geological Survey, Water-Supply Paper No. 496, p. 12. 
use the hardness of the waters of this group is rarely noticed. The removal of the hardness from the harder waters in the group is profitable only in laundries, in boiler plants operating at high capacity, and in a few other industrial plants." (b) From 56 to 100 parts per $1,000,000$, "slightly hard." "The softening of the waters in this group is profitable for nearly all laundries, and softening or treatment within boilers is necessary to obtain the best results in steam plants." (c) From 101 to 200 parts per 1,000,000, "moderately hard" to "hard." "The hardness of these waters is noticed by anyone, and its reduction is frequently worth while to make them suitable for domestic use as well as for use in industrial plants." (d) From 200 to 500 parts per 1,000,000, "truly hard," some are "excessively hard." "Their hardness can not be ignored in any use of the water that is affected by hardness."

Regarding the use of water in power laundry operations, the department of research of the Laundryowners' National Association states:

The main factor, from a laundering viewpoint, is that of quality. Even when using water containing as little as 2 grains of hardness it has been observed that a better grade of white work is secured if the water is softened. In view of this fact, it is interesting to note that many laundries that use such waters without softening them are now running the first rinse at a low suds level rather than at the customary higher rinse levels. By so doing there is less tendency for insoluble soap deposits to be thrown out of suspension in the early rinses since a smaller quantity of hardening constituents is added at the lower level. The following rinses are run at the usual high levels. This much is certain, the quality of the washing is improved when water containing 2 or more grains of hardness per United States gallon is softened. The savings with regard to supplies naturally will be less noticeable than is true when the raw water contains 4 or more grains of hardness.

Many public water supplies contain up to 100 parts per $1,000,000$ (about 5.8 grains) of hardness per gallon. Satisfactory home laundering can be done in such water by adding softening chemicals (soda ash, trisodium phosphate, borax, etc.) to the heated water at least one minute before using soap, or using a "built" or "builded" soap (which contains such materials). When soap and builder are added together, the cost of water softening is said to be practically the same regardless of the proportions of soap and builder in the mixture used. It is therefore better to add the builder first. Water is low in cost, is a good solvent, is practically inert with respect to textile fibers, and is a cleansing agent itself. As already explained soap and other detergents lower the surface tension of water, and thus increase its cleansing action.

Perfectly pure water can be obtained only by distillation. Rain water, when carefully collected, is the purest water ordinarily obtainable for the household, and is especially useful when very soft water is desired.

\section{WATER SOFTENING}

Water softening is usually effected by the soda-lime process (hydrated lime and soda ash), or some modification of it, or by the exchange-silicate process (a natural or artificial hydrous sodium aluminum silicate), or so-called "zeolite" process. The latter is in use in many households. These processes are described in publications on water treatment, and will therefore not be described here.

The exchange-silicate process is in general use in the laundry industry, although with certain waters the lime-soda process may be preferred; for example, muddy waters, waters high in iron, car- 
bonic acid, or other acid. With waters high in temporary or carbonate hardness the concentration of sodium bicarbonate in the effluent from the exchange-silicate softener may in some cases prove a disadvantage in "souring" and bluing. Rinsing in water high in sodium bicarbonate may cause trouble by the conversion of the sodium bicarbonate retained in the goods into sodium carbonate on drying and ironing. This might be overcome by adding a little acetic acid in the last rinse. The exchange-silicate softener when properly operated delivers water of nearly zero hardness; this can not be attained with the lime-soda process. With very hard waters and waters high in temporary hardness a preliminary softening is often made by the lime-soda process and the resulting partially softened water filtered and then completely softened by the exchangesilicate process.

\section{DISSOLVED IMPURITIES OTHER THAN HARDNESS}

As stated above, some waters contain iron compounds and sulphides in appreciable quantities. All natural waters contain dissolved gases, organisms, and various salts that do not precipitate soap. Iron, sulphides, manganese, and the salts which cause hardness, referred to above, are generally the compounds to be taken into account in considering a water supply for laundering operations. Waters high in alkalinity caused by the presence of alkaline sodium compounds are sometimes used, the alkalinity being corrected by a sour in the final rinse water. (See "winter damage," p. 23.) Waters containing free acid may be neutralized with a little soda ash, a precaution that is absolutely essential if corrosion of piping, heaters, and boilers is to be avoided.

\section{SOAP}

\section{GENERAL COMPOSITION OF SOAP}

All metallic salts of the higher fatty acids are, strictly speaking, soaps; but the fatty-acid salts of the alkali metals are the only ones that are soluble in water, and therefore the only ones commonly used as cleansers. Water-soluble soap is also used in the preparation of numerous toilet articles, cosmetics, and pharmaceutical products. Probably its most important function in such preparations is as an emulsifying agent; however, its detergent action is also important in many cases. The consistency of many creams, pastes, or salves may be due to the tendency of the soap in them to form jellies. Soap is also used as a vehicle for carrying various materials in the form of cream or paste. Soaps of some of the other metals are used for particular purposes, such as aluminum soaps, which are used for thickening lubricating oils and in waterproofing concrete and other materials; iron and chromium soaps, which are used in dyeing and color printing; lead, manganese and cobalt soaps, which are used as "driers" in paints and varnishes; lime soaps and lead soaps, which are used in the preparation of adhesive plasters; lime soaps, which are used in the preparation of lubricating greases; zinc and magnesium stearates, which are used in dusting and talcum powders and in rubber compounding; and magnesium oleate soaps, which have been used in solution in dry-cleaning solvents, such as 
gasoline or other flammable petroleum distillate, to prevent or reduce the fire hazard due to static electricity. These, however, are used for purposes so radically different from those which call for the detergent soaps that they will not be considered in this circular.

In addition to alkali salts of fatty acids and sometimes rosin and naphthenic acids (obtained from petroleum), all soaps contain some water and small amounts of impurities and by-products of manufacture. For various purposes certain other substances ("builders") frequently enter into the composition of commercial soaps. Among building substances may be mentioned sodium carbonate, borate, silicate, and phosphate for hardening soaps and for improving their cleansing action when used with hard water; sand, volcanic ash, infusorial earth, pumice, clay, starch, and like substances intended to aid mechanically in the process of cleaning; glycerol (glycerin), for increasing the emollient properties; sugar, alcohol, and glycerol, for increasing transparency in solid soaps and for preventing clouding and foaming in liquid soaps; colors and perfumes in many varieties. Certain colloidal clays, colloidal silicates, and colloidal organic materials are sometimes added to soaps and cleaning powders to serve both as detergents and mechanical aids in cleaning operations. Certain other materials, such as mineral onls, waxes, talc, starch, ground wood, etc., are sometimes used for specific purposes, but when added for the express purpose of cheapening the soap they should be regarded as fillers.

For toilet use or for washing delicate fabrics in rain water or other very soft water a soap should be used with little or no builders; but with hard waters these builders prevent waste and increase the efficiency of the soap by acting as water-softening agents and detergent aids. When washing greasy or badly soiled fabrics in soft water these builders increase the efficiency of the soap. However, for maximum economy where hard water must be used, it is best to add a softening agent to the heated water, stir and let stand a while to react before adding soap, even soap containing material intended to soften the water. In all cases the builders tend to increase the cleansing properties of the soap. Certain materials are often added for special purposes. For example, so-called "naphtha soap" contains a special petroleum distillate; pumice soap contains finely ground pumice and is used very extensively by mechanics for removing oil and stains from the hands; certain soaps contain special solvents, such as ethylene chloride, hydrogenated phenols, hydrogenated naphthalenes, etc.

Under special conditions such substances as sulphur, carbolic acid, mercury salts, etc., are added to medicinal soaps; tobacco extract, pyridine, etc., are added to insecticidal soaps; perborates, peroxides, etc., are added to some soaps and soap powders. These special soaps, however, will not be considered.

Animal and vegetable fats and oils are mixed esters, or more specifically, mixed glycerides of the higher fatty acids, and it is from these materials that soaps in general are made. The difference between a fat and an oil is mainly physical. The term "fat" is generally applied to those glycerides which are solid at ordinary temperatures and "oil" to those which are liquid under similar conditions. For the sake of simplicity we will use the term "fat" to cover both classes. Each fat as found in nature contains the glycerides of several different fatty 
acids, the principal ones of which are named, respectively, stearic, palmitic, and oleic acids. These occur in varying quantities in practically all fats, the solid fats containing a large proportion of stearicacid glyceride (stearin), while the liquid fats contain a large proportion of oleic-acid glyceride (olein). There are a large number of fatty-乏cid glycerides besides the three mentioned above which occur in certain fats, such as lauric-acid glyceride (laurin) in coconut and palm-kernel oils, myristic-acid glyceride (myristin) in palm-kernel oil, linoleic-acid glyceride (linolein) in linseed oil, etc.

The development of the hydrogenation process has given the soapmaker a cheaper source of fats in that it enables him to employ a number of oils which otherwise would be of limited use to him. By this process the oils (liquid fats) are hardened and deodorized, mainly by more or less complete conversion of the olein into stearin. Fish or train oil, cottonseed oil, soybean oil, and other oils are hardened and the hardened fats used in soapmaking. These hardened fats are mixed with suitable amounts of other fats to give the desirable qualities (lathering, etc.) to the soaps.

The numerous animal and vegetable fats, such as tallow, lard, olive oil, palm oil, coconut oil, cottonseed oil, soybean oil, etc., are neutral substances which may be decomposed by the aid of superheated steam (autoclave saponification) or other suitable means into two separate portions, namely, a mixture of fatty acids, on the one hand, and glycerol, on the other.

Probably the most widely used method for splitting fats into fatty acids and glycerol is the Twitchell process or some modification of it. In these processes the fat is boiled with water and the proper amount of a special organic reagent known as the "saponifier." The special reagent acts as a catalyzer; that is, accelerates the saponification, or splitting, by the water.

Saponification is the term applied to this splitting of an ester by the action of water, forming an alcohol and a fatty acid (glycerol is the alcohol in fats). This may be expressed as follows:

$$
\mathrm{C}_{3} \mathrm{H}_{5}\left(\mathrm{O} \cdot \mathrm{C}_{18} \mathrm{H}_{35} \mathrm{O}\right)_{3}+\begin{gathered}
\text { and } \\
\text { water }
\end{gathered} \mathrm{H}_{2} \mathrm{O}=\mathrm{C}_{3} \mathrm{H}_{5}(\mathrm{OH})_{3}+3 \mathrm{C}_{18} \mathrm{H}_{36} \mathrm{O}_{2}
$$

The stearic acid can be neutralized by caustic or carbonated alkali, forming soap, as follows:

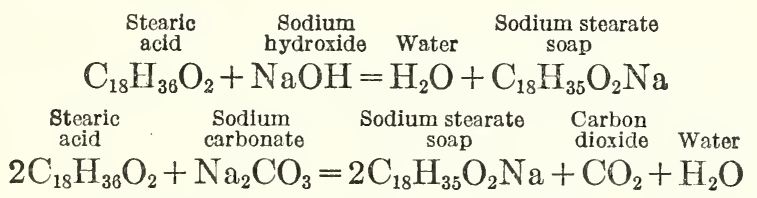

The same types of reaction take place with other free fatty acids.

It is not necessary to split the fats into glycerol and fatty acid previous to neutralizing the acid with alkali. In fact, one of the most important and one of the oldest methods in use is to treat the fat itself with caustic alkali in the presence of water, the reaction being represented by the equation

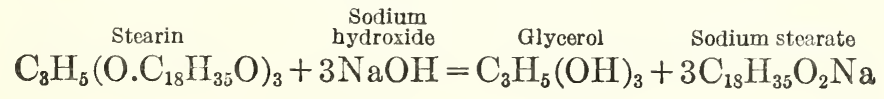


The same type of reaction occurs with all other fats. Mineral and essential oils are not true fats and with few exceptions they do not contain fatty acids. Waxes are not glycerides, but do contain fatty acids in combination with alcohols of high molecular weight. They can be saponified in the same manner as fats, but are seldom used in this manner.

Rosin (colophony) is an acid substance, and while its exact nature is not as well understood as that of the fats it may be tentatively considered to be mainly abietic acid $\left(\mathrm{C}_{20} \mathrm{H}_{30} \mathrm{O}_{2}\right)$, which reacts with alkali according to the equation

$$
\mathrm{C}_{20} \mathrm{H}_{30} \mathrm{O}_{2}+\mathrm{NaOH}=\mathrm{H}_{2} \mathrm{O}+\mathrm{C}_{20} \mathrm{H}_{29} \mathrm{O}_{2} \mathrm{Na}
$$

Certain acidic substances obtained in the refining of some petroleums, and known as naphthenic acids, have been used in Europe for the production of naphthenic soaps by neutralizing the acids with alkali.

Hard soaps are generally made with soda, while the potash soaps are soft and are more easily soluble in water than the soda soaps. The character of the fatty materials used and the method of manufacture also influence the hardness, solubility, appearance and other properties of the resulting soaps, the hard fats, such as tallow, and hydrogenated or "hardened" fats, making harder soaps generally than the more fluid fats. Rosin makes soaps softer, and it can therefore, be used best in connection with tallow and other hard fats. Coconut oil and palm-kernel oil make hard soaps that dissolve very readily in water; hence lather freely. Soap made from straight coconut oil or palm-kernel oil is said to be irritating to the skin of some people. However, it has been claimed that when superfatted such soaps are mild, and that when properly made they have no tendency to become rancid or develop acidity. Soap made from straight palm-kernel oil may develop acidity. Palm oil when used alone as the fat stock may produce a "crumbly" soap. Cottonseed oil, corn oil, soybean oil, linseed oil, etc., also impart certain characteristics to soaps made from them. Olive oil is used largely in the manufacture of textile soaps; mixed with tallow and coconut oil it is used in the manufacture of milled toilet soaps; it is also used in the manufacture of Castile soap. Red oil (oleic acid) is now used extensively to replace olive oil, especially in textile soaps.

\section{METHODS OF MANUFACTURE}

The method most generally used for the manufacture of a sodium soap is the graining or boiling and settling ("full boiled") process. This method of making soap requires close attention and control. The fatty stock, concentration of alkali solutions, temperature, amount of salt used, time of settling, etc., are all influencing factors. The neutral fats are melted, the impurities allowed to settle, and the clear fats run or pumped into the soap kettles and heated with an open steam coil. A 10 to 15 per cent solution of caustic soda (the lye drawn off as the "strong" change from a previous batch of soap may be used) is gradually added and the mixture heated by steam until the saponification is about 90 to 95 per cent complete. Salt is then added until the soap is "grained" or salted out of solution and fioats on top as a curdy mass. The steam is turned off and the salt solution containing glycerol, alkali, and impurities settles to the 
bottom. When properly settled, the salt solution is drawn off as the first "spent lye change." The soap is then thinned out by adding water and sufficient caustic soda solution to give it a slightly alkaline reaction after being thoroughly boiled. Salt is again added and the soap grained from the lye. When properly settled the lye is drawn off as the "second lye change." This process is repeated until the fat is completely saponified and the glycerol and impurities washed out of the soap. These lye changes are used for the recovery of the salt and glycerol. The soap is then boiled with a 10 to 15 per cent solution of caustic soda to insure complete saponification, and, as an alkali solution of this strength "grains" the soap, it is allowed to stand after boiling until the soap separates. The lye is then drawn off as the "strong" or "strengthening change."

The soap is then thinned with water, boiled to a uniform consistency, and allowed to settle. This settling requires from a few hours to several days, depending on the kind of soap being made, and the size of the kettle. The temperature during this settling is so regulated that the soap after delivery to the crutcher will have a temperature of about $130^{\circ}$ to $135^{\circ} \mathrm{F}$. The salt, alkali, and impurities settle to the bottom of the kettle to form the pitch water and nigre, leaving the soap on top. The soap is then run off from above the nigre and pumped to the "crutcher" or mixer, which consists essentially of a cylindrical steel or iron tank equipped with a worm agitator, and usually steam jacketed. Alkaline sodium salts or "builders" are added at this stage. Perfumes, colors, and other ingredients required in the completed soap may also be added. The temperature during crutching ranges from $200^{\circ} \mathrm{F}$. down to $135^{\circ} \mathrm{F}$., depending upon the grade of soap and the amount of "builders", added; therefore, there will be a loss of certain perfumes by volatilization. When the "builders" or other added substances are thoroughly incorporated in the soap by crutching, the mixture is run into "frames" to cool and harden. The frames are essentially iron boxes, the four upright movable sides being fastened together and to a platform (called a "frame bottom") on wheels. When the soap has hardened sufficiently (generally about three to seven days), the sides of the frame are removed (called "stripping") and the large solid cake of soap, called the "frame of soap," is cut with wires by hand or by a "slabber" into slabs of any desired size. The "slabber" is a machine with parallel wires at a uniform distance apart. These slabs are then divided into cakes or bars by the "cuttingtable," a machine performing two cutting movements at right angles to each other. In nonmilled soaps (laundry soaps, floating soaps, etc.) the cakes or bars are allowed to dry somewhat in the drying room to form a thin, hard surface film, pressed by automatic presses, and wrapped and packed by machinery.

In making soaps containing rosin the rosin may be melted with fats and run into the kettle at the outset, or it may be neutralized ("saponified") separately with sodium carbonate and the rosin soap run into the kettle just before the addition of alkali for the "strong change." Sometimes the rosin itself is added at this stage. If fatty acids and no neutral fats are used for making the soap, the "saponification" (neutralization in this case) may be effected with either sodium carbonate or caustic soda. No glycerol will be "split off" as it has previously been removed in the cleavage of the fats into 
fatty acids and glycerol by the Twitchell, autoclave saponification, or other process.

In the case of toilet and white floating soaps, where a neutral product is desired, the pitch water and nigre are often drawn off and the settling process repeated until the desired neutrality is obtained by settling out the excess of alkali.

The soap maker also uses two other processes known as "cold" and "half," or "semiboiling." The cold process is the simplest method of soap making and requires the least equipment. However, no separation of soap is effected, the product contains the glycerol and impurities, and the saponification is frequently not completed, yielding a product containing free fat which may later produce rancidity, or containing free alkali. The fats used should be as pure as obtainable and in some cases it might be advisable to bleach them. The water solution of lye (caustic soda or caustic potash) at room temperature is added slowly, with stirring, to the melted fat (temperature about $100^{\circ} \mathrm{F}$.), and the mixture allowed to stand at room temperature for some time in order that the saponification may continue as a result of the heat developed by the chemical reaction. The soap may then be cut into cakes or bars and pressed. The oil and lye solution are usually mixed in a crutcher and crutched until the proper consistency is obtained (for example, until a finger drawn over the surface of the soap leaves a slight impression). The mixture is dropped into a frame and allowed to stand covered for some time. "Builders," etc., may be added during the crutching. The soap is then "slabbed" and cut into cakes or bars. The half, or semiboiling process is similar to the cold process, except that the fats (or fats and rosin) are heated to about $150^{\circ} \mathrm{F}$. in a jacketed kettle or a crutcher and the lye solution added slowly, so that the heat of reaction will raise the temperature to about $180^{\circ}$ to $200^{\circ} \mathrm{F}$. These soaps may also be "builded."

The user of soap should bear in mind that there are many varieties of soaps, and what is satisfactory for one purpose may be unsatisfactory or too expensive for another.

\section{VARIETIES OF SOAP}

\section{TOILET SOAPS}

Toilet soaps should be neutral, since excess alkali is injurious to the skin. Builders, such as sodium carbonate and sodium silicate, having a similar effect, should also be absent. Free-lathering soap is generally desirable, and since a soap made from tallow or hardened fats lathers slowly and coconut-oil soap lathers very freely, usually 20 to 30 per cent of this oil is mixed with 70 to 80 per cent of tallow, palm oil, or hardened fats to produce a soap that will lather freely. Olive oil and potash are frequently used in toilet soaps to produce better lathering qualities.

(a) Milled Toilet Soaps are prepared by first obtaining a finely divided (flake or powder), pure, dry soap, adding perfume, if desired, and compressing into cakes. More delicate perfumes can be used with this class of soaps, since the perfume is mixed in the process of milling, than with ordinary soaps in which the perfume is added before the soap is dried. 
A common method of manufacturing such soaps consists in running the hot liquid soap from the kettle directly over water-cooled, sometimes brine-chilled rolls, which congeal the soap in a thin film on the rolls. The soap is then scraped off in the form of thin ribbons or flakes which fall on an endless belt and are carried through a drier to reduce the moisture content to 12 to 15 per cent. The ribbons or flakes are run into a mixer, called an "amalgamator," and perfume and coloring matter (medicants in the case of medical soaps) are incorporated by a thorough mixing. The soap is then "milled" by passing it between two or more heavy rolls until it has a smooth finish, and the added materials are uniformly blended or incorporated. The thin ribbons or flakes of soap scraped from the last roll are then "plodded." A "plodder" is a machine in which the flakes are forced under great pressure through a "shaping plate" to give the desired size and shape. These bars are cut into the desired lengths, which are fed into a press and stamped into cakes. The cake is then ready for wrapping and packing.

Although it is not the common practice to-day, formerly a very small amount (about 0.5 to 1 per cent) of high-grade zinc oxide or zinc stearate was carefully added to a white soap during milling to remove any translucency that may be caused by "plodding." It has been claimed that the zinc compounds would also remove any yellowish cast, but such an effect does not appear probable. Special blue dyes have been used in very small amounts to mask a slight yellow color in such soaps.

Some toilet soaps are put on the market in the powdered form. In this case a material, such as powdered starch or powdered talc, is usually added to prevent caking.

(b) Floating Soaps are generally made by the boiling and settling process, except that minute air bubbles are incorporated into the hot soap by a specially constructed crutcher, by crutching at a high rate of speed, or by reversing the direction of the screw several times during the crutching. These air bubbles are so small as to be almost invisible and so numerous that they not only make the soap lighter than water, but also largely increase the surface of the soap exposed to water when used, and, therefore, render it more quickly soluble than the same soap would be without the bubbles.

In the manufacture of these soaps 25 to 30 per cent of coconut or palm-kernel oil is used to improve the lathering and detergent qualities of the tallow or hardened fats. Other fats, such as white grease or lard, may be mixed with these.

(c) Castile Soap.-One of the first, if not the first, hard cake soaps that entered largely into commerce was made from pure olive oil and soda with no admixture of any other fat. Such a soap was known as Castile, Marseilles, or Venetian soap. The United States Pharmacopœia ${ }^{4}$ describes Castile soap made from olive oil and caustic soda and gives tests for its purity.

(d) Transparent Soaps were originally made by dissolving soap in alcohol, filtering, and evaporating off most of the alcohol. This procedure has been practically discarded because of the expense. Transparency is generally due to the presence of alcohol, glycerol, or sugar in the soap. Rosin has been used in making such soaps.

- The definition of Castile soap in the trade is now before the Federal courts for decision. 
The materials used in making transparent soaps should be carefully selected for purity and color, especially when clearness and lightness of color are desired in the finished product. The sugar, alcohol, or glycerol is usually added during the crutching. Transparency formerly was considered an indication of freedom from impurities, but is actually no indication whatever of purity or quality.

(e) Liquid ToIlet Soaps are water solutions, generally of a neutral coconut-oil potash soap, and contain glycerol, sugar, or alcohol added to lower the freezing point and to prevent cloudiness and foaming in the container. Sometimes the coconut oil is replaced in part by palm-kernel oil or other vegetable oil, such as olive oil. The glycerol is probably an unobjectionable addition, since it has emollient properties, but sugar can have no beneficial action on the soap itself and may be objected to on account of its tendency to leave the hands sticky. The oil is run into a jacketed kettle equipped with a stirring device, heated to about $120^{\circ} \mathrm{F}$., and the proper amount of a water solution of caustic potash (potash lye) added. After the saponification is complete, the other ingredients (glycerol, alcohol, etc.) are added, the desired volume of water is run in, and the mixture stirred until the soap is dissolved. Color or perfume is stirred in after the solution has cooled. Most of the liquid soaps are chilled to at least $60^{\circ} \mathrm{F}$., and preferably lower, and filtered before packing to remove the unsightly, slimy precipitate of partially hydrolized soap which is the result of dilution. As a rule, it is best to hold the liquid soap in storage for some days before filtering, in order that the finely divided colloidal particles may agglomerate to a size sufficient to be retained by the filtering medium. Otherwise the solution may not stay clear and bright.

Liquid soap as generally used contains about 12 to 20 per cent of anhydrous soap. The soap manufacturers also put out a concentrated liquid soap containing from 40 to 50 per cent of anhydrous soap, and a pasty soap known as "liquid soap base." The latter can be mixed with distilled water and glycerol or alcohol to yield a liquid soap with the desired content of anhydrous soap.

$(f)$ Shaving Soaps must possess not only the properties of firstclass toilet soaps, but must furnish a very copious lather, which will remain on the face for some time without drying. This lather should soften the beard without injuring the skin. These soaps should have no unpleasant odor and usually contain little or no perfume.

The fat used in making shaving sticks and tablets generally consists of a mixture of tallow, stearic acid, and coconut oil. The alkali is generally a mixture of caustic soda and caustic potash. Glycerol is also generally present. Sometimes a small quantity of a gum, such as gum tragacanth, is crutched in to aid in holding the lather.

Shaving powder may be produced by thoroughly drying the above soap and then grinding or pulverizing. From 3 to 5 per cent of starch is sometimes mixed in to prevent the powder from caking.

Shaving creams are usually potash soaps made by saponifying a mixture of stearic acid and coconut oil with caustic potash. These creams frequently contain an excess of unsaponified stearic acid; that is, are superfatted. Castor oil and lanolin have also been used. Added water and glycerol are also generally present.

(g) TAR SoAps are made by mixing 5 to 20 per cent of tar, generally pine tar, with a soap base. A small amount of aniline black or lamp- 
black is often added as coloring matter. Coconut oil frequently forms a part of the fat base to increase the lathering property.

(h) Hand Grit Soaps are often called pumice or sand soaps and are marketed both in the cake and the paste forms. The cake soaps are generally made by crutching a very fine abrasive (usually pumice or "silver" sand) into a cold made or semiboiled soap made from coconut oil or palm-kernel oil, or a mixture of these oils with tallow or other fat. After the soap is "set," it is slabbed, cut into cakes, dried slightly, pressed, and packed.

The paste may be made by dissolving the soap base in two or three times its weight of hot water and mixing in the desired amount of the abrasive. Glycerol is generally added to keep the paste soft. The pastes may also contain an added solvent for grease. They may also be made by crutching the abrasive, glycerol, etc., directly into a potash (soft) soap.

\section{SALT WATER OR MARINE SOAP}

Soap for use with salt water is made from pure coconut oil, pure palm-kernel oil, or a mixture thereof and the necessary alkali, generally caustic soda. These soaps usually contain definite amounts of sodium carbonate and sodium chloride (salt). Such soaps are less easily precipitated by salt water than sosps made from other fats. Although such soaps may be made by the "semiboiling" process, it is usually made by the "full-boiling" process (or some modification of it) in order to recover the glycerol.

\section{LAUNDRY OR COMMON SOAPS}

(a) Laundry Cake or Bar Soap is probably used in larger quantities in the household than any other. Ordinary laundry soap is generally made of caustic soda and tallow, with some rosin. The tallow is frequently replaced partly or wholly by grease, cottonseed, coconut, and palm-kernel oils or hydrogenated fish and vegetable oils. Rosin is added to increase the lathering qualities of the soap and is an aid in this respect when used in an amount not more than one-third of the total fat. Large amounts tend to make the soap sticky and too soluble and to harden the fabric washed with it. Sodium carbonate is added to the soap to increase its water-softening and detergent properties where it is to be used with hard waters.

Sodium silicate is also added to soaps to increase their detergent and water-softening properties, especially where the soaps contain 20 to 30 per cent of coconut oil and are intended for use in hard-water districts. Borax and trisodium phosphate have similar action to sodium carbonate and sodium silicate.

These soaps are usually made by the boiling and settling process ("full boiling"), although other processes may be used.

(b) Chip Soaps and Powdered Soaps designed for laundry purposes are generally made from tallow, greases, or hydrogenated fish or vegetable oils combined with caustic soda. Chip soaps for textile use usually contain some olive or palm oil, also oleic acid. Chip soaps designed for fine laundry use, such as washing laces and fine fabrics, usually contain a considerable amount of coconut oil. They are made by running the liquid soap made by the "full-boiled" process over cooling rolls, which reduce the soap to a thin ribbon.

$118735^{\circ}-30 \longrightarrow 3$ 
These ribbons are passed through driers, which reduce the moisture content to 10 to 15 per cent, after which the soap is either run through rolls, which reduce it to thin flakes or chips, or through disintegrators which pulverize it to a fine powder. Modern laundry practice frequently demands a soap that will dissolve quickly when added directly to the wash wheel instead of being made, as was formerly the case, into a stock solution by dissolving definite amounts of the soap and alkali in a definite volume of water. There seems to be an increasing interest, however, in liquid soaps on the part of present-day laundry owners. In large laundry plants soap solutions are being piped directly to wash wheels, pumps being used to circulate the stock soap solution. Chip soap should be free from objectionable odor, should contain no rosin, and should rinse readily from fabrics.

\section{SOAP POWDERS}

Soap powders, sometimes called washing powders (not to be confused with "powdered soap" mentioned on p. 15), should be entirely soluble in water and should consist of a uniform mixture of soap and sodium carbonate or other builders in powdered form. Soap powders usually contain 15 to 20 per cent of anhydrous soap and the balance of crystallized sodium carbonate, often with the addition of borax, trisodium phosphate, etc. They are used very extensively for general household work owing to their ease of application, solubility, and cleansing qualities. They are also used in powerlaundry practice when the proper proportion of builder is incorporated with the soap.

There are several methods of manufacturing soap powder, but the one generally used is known as the "continuous process." The soap is run hot from the kettle into a crutcher or mixer and mixed thoroughly with a concentrated solution of sodium carbonate (soda ash) or other builders. The mixture is run over chilling rolls to chill the soap and crystallize the sodium carbonate. The product is scraped off the rolls and screened, the coarse particles going to a grinder and the finer portion being packed by machinery. These powders are also made by dissolving soap and sal soda or soda ash in water and spraying or "atomizing" the solution, which gives a product that only requires screening to remove larger particles. As these powders contain a high percentage of combined water (forming a part of the crystallized sodium carbonate), they are usually wrapped in paraffin paper to prevent loss of this water with a corresponding reduction in weight.

\section{SCOURING POWDERS}

A scouring powder should consist of a uniform mixture of soap powder and an insoluble abrasive. The abrasive is usually powdered pumice, volcanic ash, quartz, marble, or feldspar. The abrasive is mixed with the soap and sodium carbonate in a special mixer.

\section{SCOURING CAKE SOAP}

Scouring cakes consist largely of abrasive material, such as silex or sand, powdered pumice, volcanic ash, feldspar, etc., with a binder of soap, and frequently considerable sodium carbonate. 
Since a higher lathering property is generally required of scouring cake soap than of soap powder or scouring powder, coconut oil is often used in whole or in part as the fat base. The fat is saponified with caustic soda in a crutcher, and sodium carbonate solution, a small amount of sodium chloride solution and the abrasive added. After mixing thoroughly, the mixture is framed and cut or run directly into molds and allowed to harden.

\section{SOFT SOAPS}

Soft soaps are paste soaps made from vegetable oils of "low titer" (those which yield fatty acids of low solidification point), other than coconut oil, and caustic potash or a mixture of caustic soda and caustic potash. The majority of the soft soaps, particularly automobile soaps, have as their basis linseed oil, soya-bean oil, or corn oil, or the fatty acids of these.

As the recovery of glycerol is practically impossible in the manufacture of potash soaps from fats, oleic acid, known as "red oil," often forms a part of the fat base and potassium carbonate a part of the alkali. Automobile soaps frequently contain a small excess of the neutral fat. The United States Pharmacopœia gives a formula for making "U. S. P. Soft Soap."

After standing for some time, especially in cold weather, soft soaps frequently have apparently crystalline areas distributed through them. This behavior, known as "figging," is apparently due to the crystallization of the higher melting potassium stearate and palmitate from the matrix of potassium oleate or similar low melting soaps. "Figging" may be induced by the careful addition of caustic soda to the caustic potash used for the saponification, by using some fatty material high in stearin in the fat base, and by other means. Such soaps are often referred to as "fig" soaps.

\section{MISCELLANEOUS SOAPS}

(a) Liquid Laundry Soaps have been used to a limited extent in some power laundries and textile mills. These soaps are generally made from oleic acid (red oil) and potash, or a mixture of soda and potash and contain, besides a large amount of water, various organic solvents, such as ethylene dichloride, "hexalin," etc. Sulphonated oils are also used in the manufacture of liquid soaps for certain textile operations.

(b) Mottled or Marbled Soaps are made only to a slight extent in this country and probably for export only. These soaps are made by adding coloring matter (ultramarine, ocher, copperas, etc.) to the soap (usually in the crutcher) just before the soap is run into the frames. The coloring matter is not thoroughly incorporated, thereby producing the mottled appearance.

(c) Hand Soaps for Use Witmout Water are soft or paste soaps for removing oil, grease, etc., from the hands where water is not available. They usually consist of a potash soap base with or without a fine abrasive, such as pumice, and contain mineral oil or free or unsaponified fatty oil and a large amount of water. Glycerol may also be present. Some essential oil is generally present as a perfume. 
(d) Hard Water Soaps. - In order to supply soaps that will lather freely in hard waters, the soap manufacturers have increased the alkaline builders and substituted coconut oil for rosin in the yellow laundry soaps, producing the so-called white laundry soaps. The alkaline builders are usually added in the crystallized form; that is, they are in solution in what is equivalent to their water of crystallization and when allowed to cool will crystallize in the soap to a solid state. These builders often contain about 35 per cent of the alkaline salt and 65 per cent of water of crystallization. The addition of these alkaline builders in increased quantities to domestic or household laundry soaps has increased the water content of these soaps. The pure soaps free from builders contained 28 to 30 per cent of moisture, while the yellow laundry soaps when builded contain 36 to 38 per cent of moisture, and the white laundry soaps 38 to 42 per cent of moisture.

Besides the white laundry soaps there are others made from coconut or palm-kernel oils by the cold process with little or no admixture of alkaline salts ("builders") and usually superfatted, that are used extensively in hard-water districts.

\section{ALKALINE CLEANSERS}

These materials are used directly for cleaning purposes, water softening, and as detergent aids with soap solutions. Mlost of them are also used for "building" laundry soaps.

\section{AMMONIA WATER}

Ammonia water is generally used in the home as the so-called "household ammonia." These preparations may consist of a solution of ammonia gas in water or of such a solution containing small amounts of soap and sodium carbonate or borax. The latter are often cloudy or turbid solutions. They are sometimes perfumed. These preparations are frequently used in cleaning glassware and are sometimes added to the water used for washing clothes to aid in water softening and in the removal of soiling matter.

\section{2. "POWDERED AMMONIA"}

The so-called "powdered ammonia" or "ammonia in powdered form" usually consists of a mixture of an ammonium salt (generally ammonium sulphate; sometimes a mixture of this salt and some ammonium chloride), and sodium carbonate. Sometimes such preparations may contain considerable amounts of sodium chloride, an inert ingredient from the standpoint of detergency. When dissolved in water, the ammonium salts and the sodium carbonate react chemically and liberate ammonia, which is dissolved by the water. These preparations are used for cleansing purposes and as detergent aids in conjunction with soap. They should be entirely soluble in tepid water and iree from caustic alkali or inert fillers.

\section{BORAX}

The borax found on the market is sodium tetraborate with 10 molecules of water of crystallization $\left(\mathrm{Na}_{2} \mathrm{~B}_{4} \mathrm{O}_{7} \cdot 10 \mathrm{H}_{2} \mathrm{O}\right)$. Formerly the borax supply of this country was derived principally from the 
minerals-borax, colemanite, and ulexite. The discovery in 1926 in the Mohave Desert, Kern County, Calif., of enormous deposits of the mineral kernite (also called rasorite) affords a source of supply that will supersede all others. Kernite is sodium tetraborate with only 4 molecules of water of crystallization $\left(\mathrm{Na}_{2} \mathrm{~B}_{4} \mathrm{O}_{7} \cdot 4 \mathrm{H}_{2} \mathrm{O}\right)$. The material is mined, dissolved in water, the solution filtered to remove clay and the water allowed to evaporate until recrystallization takes place. Owing to the greater content of water of crystallization about 1.4 tons of pure borax can be made from 1 ton of pure kernite. Borax is used to soften water, as a cleansing agent, as a component of soap powciers, and as a "builder" in some soaps. It should be entirely soluble in water.

\section{SODA ASH}

Soda ash is anhydrous sodium carbonate $\left(\mathrm{Na}_{2} \mathrm{CO}_{3}\right)$ and is usually found in commerce in two grades, viz, "58 per cent ordinary or light" and "58 per cent dense" (about 58 per cent of sodium oxide and about 42 per cent of carbon dioxide). Chemically, the two grades are identical, and perform the same functions. The dense grade is used where small bulk is desirable; for example, in glass manufacture. Soda ash is used as a water softener, soap "builder," detergent aid in laundering, and as a cleanser (bottle and dish washing, metal cleaning, etc.). It should be entirely soluble in water and free from caustic alkali.

\section{LAUNDRY SODA (WASHING SODA)}

Laundry soda (washing soda) is a so-called "modified soda" or "neutral soda." Modified sodas are mixtures of varying proportions of sodium carbonate and sodium bicarbonate. The latter insures the absence of caustic alkali. Such sodas are milder alkaline salts than soda ash or straight sodium carbonate. One of the modified sodas is known in the trade as "sesquicarbonate of soda." These sodas should be completely soluble in water. They are used in laundering and other cleansing operations.

\section{SAL SODA ("WASHING CRYSTALS" OR "SODA CRYSTALS")}

Sal soda ("washing crystals" or "soda crystals") is sodium carbonate combined with 10 molecules of water of crystallization $\left(\mathrm{Na}_{2} \mathrm{CO}_{3} \cdot 10 \mathrm{H}_{2} \mathrm{O}\right)$. This compound contains over 60 per cent of water, and when the water is expelled by heat or otherwise the clear crystals disappear and the material becomes an opaque powder with a corresponding increase in alkaline strength per pound (complete expulsion of the water converts it into anhydrous sodium carbonate). Sal soda is readily soluble in water and is used as a detergent and water softener.

\section{MONOHYDRATE CRYSTALS OR GRANULAR SODIUM CARBONATE}

This compound is sodium carbonate with 1 molecule of water of crystallization $\left(\mathrm{Na}_{2} \mathrm{CO}_{3} \cdot \mathrm{H}_{2} \mathrm{O}\right)$. It is used in cleansing operations (dairies, metal cleaning, etc.). Many power laundries use 58 per cent soda ash. 


\section{\&. CAUSTIC SODA (LYE), (DRAIN PIPE CLEANER)}

Caustic soda or sodium hydroxide is marketed in a number of grades varying from about 98 per cent sodium hydroxide $(\mathrm{NaOH})$ to about 78 per cent. It is marketed in various forms, as lump, flake, ground, and powdered caustic, and as a concentrated solution. The ground or powdered caustic is said to be quite stable against deliquesence when left in an open container. Ordinary lye or concentrated lye is generally a grade of caustic soda containing from 90 to 94 per cent of sodium hydroxide.

Owing to the very corrosive action of caustic soda upon the skin, it should be handled with great care. It is used in certain cleansing operations, soap making, water softening, etc. It is also used, either as such or mixed with aluminum turnings, for cleaning drain pipes. Such use depends upon its action on the accumulated grease; however, at times the soap so formed apparently accumulates more rapidly than it can be dissolved by the water and, hence, increases the stoppage. The use of the more expensive caustic potash would probably be more satisfactory, as this compound would convert the grease into a soft soap which is more readily dissolved by water. Caustic soda and caustic potash corrode lead pipes and attack the surface of enameled sinks, etc., and therefore should be kept out of contact with the enamel and not used frequently, if at all, in lead pipe.

Adequate directions for the domestic preparation of soap from household grease and caustic soda are usually given on the labels on lye containers. For example, such a soap may be made as follows: Carefully add the contents of a small can of household lye (containing approximately $5 \frac{1}{2}$ ounces of lye which should be at least 94 per cent caustic soda) to an iron kettle containing $1 \frac{1}{2}$ pints of cold soft water. Stir until all is dissolved, and allow the solution to cool until it is just lukewarm.

In another vessel melt $2 \frac{1}{2}$ pounds of clear grease, lard, or tallow, let the melted grease cool until it is just warm to the hand; then pour the solution of lye slowly into the melted grease, stirring the mixture in the meantime. After the lye has been added, stir the mixture for about 10 minutes until it is well and evenly mixed, and then pour it into a suitable mold. Cover and set in a warm place for a day or two; then cut into any desired shape with thin twine or a fine wire.

The grease, lard, or tallow must be clean and free from salt. Care must be taken to stir the lye in to the grease, not the grease in to the lye. If the soap is streaky, with greasy layers, showing that the fatty matter is not thoroughly combined with the lye, owing to improper stirring, put it into a pan or other vessel with 1 pint of soft water and boil until the soap is melted and clear. Pour into a mold, wrap to keep hot as long as possible, and set aside for two or three days.

A soap made according to the abore procedure should be suitable for rough cleaning or washing operations.

\section{SPECIAL ALKALIES}

"Special alkalies," also known as "causticized ash," are mixtures of caustic soda and soda ash, and are usually graded in the trade according to the percentage content of actual sodium hydroxide or caustic soda. These products are used in cleansing operations where a strong alkali is needed, or where the bactericidal action of a strongly alkaline solution is necessary (as in a bottle wash). 


\section{TRISODIUM PHOSPHATE}

Theoretically, this compound has the chemical formula $\mathrm{Na}_{3} \mathrm{PO}_{4} \cdot 12 \mathrm{H}_{2} \mathrm{O}$. Technical trisodium phosphate is a white, finelygranulated (crystalline) product and usually contains a small amount of sodium hydroxide or sodium carbonate owing to the process of manufacture. It often contains small a mounts of disodium phosphate, borates, and fuorides. This material usually contains about 56 per cent of combined water, is readily soluble in water, and is a mildly alkaline salt. It is suitable for a variety of cleaning purposes; for example, dishwashing, bottle washing, laundering, and cleaning flcors, painted surfaces (in dilute solutions), most metals, type, dairy equipment, oil tanks, etc. It is also used as a water softener, soap "builder," etc. Many washing powders on the market consist of trisodium phosphate or mixtures of this material with soda ash, borax, soap, and other detergents. Mixtures of trisodium phosphate, sodium silicate, and soap have been used for cleaning aluminum. The sodium silicate prevents harmful attack of the metal by the alkaline salt. A mixture of about 60 per cent of anhydrous sodium carbonate and about 4.0 per cent of crystalline trisodium phosphate has been suggested as a satisfactory washing powder for dairy cleansing. ${ }^{5}$

\section{SODIUMI SILICATE}

There are a number of silicates of soda for various uses, the differences being in the ratios of sodium oxide $\left(\mathrm{Na}_{2} \mathrm{O}\right)$ to silica $\left(\mathrm{SiO}_{2}\right)$. Special grades in the solid form and as solutions in water are made for use in the manufacture of soap (a "builder" to serve as a water softener and detergent aid). The solution in water is known as "water glass." Sodium silicate is also used in the preparation of various cleaners for metals, etc.

\section{COLLOIDAL CLEANING POWDERS}

Several preparations are marketed under this general title. Various materials are used to act as detergents by forming colloidal solutions in water; for example, causticized starch or starchy matter, causticized cellulosic matter, certain colloidal clays, etc. The colloidal matter is mixed with such substances as soda ash, trisodium phosphate, washing soda, borax, and soap. Artificial sodium alumino-silicate is also used as a colloidal cleaner. These cleaners may be used directly for cleaning purposes. They are generally used as alkaline assistants or detergent aids in conjunction with soap in laundering operstions.

\section{FOTASSIUM COMPOUNDS}

Caustic potash and potassium carbonate are used in the manufacture of soft soaps, liquid soaps, shaving soaps, and dry-cleaning soaps. For general cleaning purposes, the cheaper sodium salts are in general use.

${ }^{6}$ Phillips, A. W., Mack, M. J., and Frandsen, J. H., Washing Powders for Dairy Use, Mass. Agrl. Expt. Station Tech. Bull. No. 13; May, 1928. 


\section{MISCELLANEOUS DETERGENT AIDS}

\section{BLEACHING AGENTS}

Bleaching is a chemical process and, in addition to the whitening of textile fibers, has a definite value in the removal of certain stains, mainly of an organic nature. A bleach does not necessarily eliminate the discoloring substances from a fabric; if soluble compounds are formed they will, of course, be removed in the subsequent rinsing: On exposure to oxidizing or reducing conditions, depending upon the type of bleach used, the color may reappear. Both oxidizing and reducing bleaches are used in the laundering of textile fabrics. The former includes chlorine compounds, peroxides, perborates, permanganates, and ozone. The reducing bleaches are sulphites, hydrosulphites, and oxalic acid. Peroxides are used to only a slight excent in the laundry industry, but they are coming more into use for the bleaching of wool, silk, and dyed cotton goods. Hydrogen peroxide may be used with silk and wool. Sodium perborate is quite stable and is used as a component of some washing powders or soap powders. Potassium permanganate has been used in a small way on wool. It can be used in either an alkaline or acid solution, but apparently is more efficient in an acid solution. When used in simple aqueous solution or in an alkaline solution, the separated manganese oxide is removed by a suitable reducing agent, such as sodium bisulphite or oxalic acid, avoiding an axcess.

Ozone bleaches well when allowed to act on fabrics before or during the drying in drying rooms. The fabries are less attacked then in the hypochlorite method but the process requires extra handling of the fabrics and increases the time of the laundering operation.

The common and most extensively used laundry bleach is sodium hypochlorite, known in the trade as "Javel water." In laundry practice the bleach is generally used in an alkaline bath, especially in the bleaching of fabrics of vegetable origin, such as cotton and linen. The bleaching solution should be free from calcium and magnesium or other substances that form insoluble soaps. Sodium hypochlolite, or "soft bleach," may be made by treating "bleaching powder" or "hard bleach" (chloride of lime, calcium hypochlorite) with an squeous solution of soda ash; treating an aqueous solution of soda ash or caustic soda directly with chlorine; and by electrolyzing an aqueous solution of sodium chloride. The laundry owner generally prepares sodium hypochlorite solutions of a concentration giving 1 per cent of "available" chlorine. In some cases solutions are made up to 5 per cent, and then diluted.

Unless controlled, bleaching is probably the most destructive of the various operations in laundering, especially to delicate fabrics. Hypochlorite should never be usea to bleach sillis and woolens as it damages these fibers. Cotton and linen fibers may be appreciably damaged unless the chlorine concentration, the temperature, and the time are carefully controlled. No bleach ordinarily should be used on colored or dyed goods. Metallic impurities in the scil or dirt on garments may promote the destruction of fibers by hypochlorite bleach.

Reducing bleaching agents are used in the textile trade more extensively than in the laundry industry. Sodium bisulphite is generally used. This compound is a combined bleach and sour, may be safely used on silks and wools, and is less harmful to cotton and linen 
fabrics than are the oxidizing bleaches. Oxalic acid is also a combined bleach and sour, but its use is restricted by cost and by its more pronounced effect upon fibers when concentrated by drying; it requires very thorough rinsing.

In many cases bleaching can be omitted if the household washing has been properly done. Whenever possible, the bleaching should be accomplished by exposure to sunlight and moisture; however, these agents may sometimes be deleterious to the fabric, as, for example, in the case of weighted silk or certain dyes.

\section{SOURS}

Sours are either acids or compounds which yield acids on solution in water. A sour is used in laundry practice to neutralize any alkaline compounds remaining in the fabrics, decompose any oxidizing bleach left in the goods, dissolve certain stain-forming compounds, and to prevent starched goods from yellowing when ironed.

When goods have been bleached too heavily with an oxidizing bleach, oxycellulose may be formed. Any alkali left in the fabric, especially under the influence of the ironing temperature or that of storing, reacts with the oxycellulose, forming a yellow compound. Alkali may accelerate any tendency of starches to yellow at ironing temperatures, and will affect the tint of certain blues. Wool and silk withstand the action of strong sours in fairly concentrated solutions, but cotton and linen are injured by some sours, depending upon the nature of the sour, its concentration, and the temperature. The sours generally met with in the laundry trade are acetic acid, sodium bisulphite, oxalic acid, sodium acid fiuoride, and sodium fluosilicate (sodium silicofluoride). A mixture of oxalic acid and sodium fluosilicate is sometimes used. A mixture of oxalic and acetic acids has been widely used. Sodium bisulphate has been used as a laundry sour with precautions as to amounts and rinsing, but its use is inadvisable on account of its deleterious efiect if left in the goods. Oxalic acid and sodium bisulphite should not be used with colored or dyed goods. Acetic acid and the fluoride type of sours are harmless to cotton and linen.

In certain districts it has been observed that occasionally some garments when hung outdoors to dry during the winter months are seriously attacked and weakened, in some cases finally falling to pieces. Recent work carried out by the Bureau of Standards on this so-called winter damage indicates that if the final rinsing leaves the clothes slightly alkaline from sodium compounds, they may become yellow at ironing temperatures. If the final rinsing leaves the clothes slightly acid and the clothes are exposed to certain atmospheric conditions, they may be attacked, giving rise to "winter damage." In order to prevent goods from becoming harmfully acid when hung out of doors during winter, a special alkaline treatment was devised. The goods are rinsed with clear water at least once after the sour. Then calcium bicarbonate is formed in the final rinse by the action of sodium bicarbonate and calcium chloride added separately. This may be carried out as follows: Dissolve about 2 pounds of sodium bicarbonate in 3 to 5 gallons of water and add the solution to the wash wheel. Run the wash wheel for 3 minutes, add a solution of 1 pound of calcium chloride in 3 to 5 gallons 
of water, run the wheel for 5 minutes, and dump. The exact amounts of these reagents required will depend upon the conditions involved and the volume of water in the washer or tub. A small amount of calcium carbonate remains in the goods when they are dried. This process was used during the past winter in two New England laundries which reported a material decrease in the amount of "winter damage." This study will be reported in detail in a publication by the bureau.

\section{BLUINGS}

Bluing is primarily intended to mask a yellow, but is sometimes used in an attempt to hide bad color due to faulty washing. It is doubtful, however, if bluing can cover up poor washing. The most common substances used in laundry household bluing are indigo, soluble Prussian blue, ultramarine, and blue aniline dyes. As a rule, the most satisfactory materials for bluing are indigo and aniline blue, which are not readily affected by weak alkalies or acids. Prussian blue is decomposed by weak alkalies, such as ammonia or even soap, and may thereby produce rust spots upon the goods. The aniline blues (coal-tar dyes) are in general use in the power laundries of this country. In these laundries bluing is usually carried out in the souring bath after the souring has been accomplished. Wool and silk have a great attraction for dyes, and if blued at all much care should be exercised.

\section{LAUNDRY STARCH}

Starch from various sources has practically the same composition, but differs greatly in the size and character of the grains and in its suitability for various purposes; for example, stiffening of clothes. Although rice starch is said to be the best for laundry use, a "thinboiling" mixture of corn and wheat starches is much used in this country. In the process of ironing part of the starch may be changed to dextrin, adding to the gloss and stiffness. Gum arabic and wax; for example, paraffin, often are added to starch for home work to increase the gloss. In addition to giving a pleasing finish, starch protects fabrics to some extent in that dirt or soiling matter is not so readily ground into them.

\section{REFERENCES}

Whipple, G. W., The Value of Pure Water. John Wiley \& Sons.

Foulk, C. W., The Value of Softened Water. Ind. Eng. Chem., News Edition; Aug. 20, 1924.

Collins, W. D., The Industrial Utility of Public Water Supplies in the United States. U. S. Geological Survey, Water-Supply Paper No. 496. Farmstead Water Supply, U. S. Department of Agricuiture, Farmers' Bulletin No. 1448. Thomssen, E. G., Soap-Making Manual. D. Van Nostrand Co.

Meerbott, P. B., and Stanislaus, I. V. Stanley, American Soap Makers' Guide, Henry Carey Baird \& Co., New York, N. Y.

Lamborn, L. L., Modern Soaps, Candles and Glycerin. D. Van Nostrand Co.

Martin, Geoffrey, The Modern Soap and Detergent Industry. Crosby Lockwood \& Son (London).

Webb, E. T., Soap and Glycerine Manufacture. Davis Bros. (London).

Deite, C., Manual of Toilet Soapmaking. D. Van Nostrand. Co.

Brannt, Wm. T., The Soap Maker's Hand Book. Henry Carey Baird \& Co.

Mitchell, R. W., Castile Soap. Monograph published by Lockwood Brackett Co., Boston, Mass.

Laundryowners' National Association, La Salle, Ill., Manual of Standard Practice for the Power-Laundry Washroom. 
Laundryowners' National Association, The Conservation of Textiles.

The Procter \& Gamble Co., Cincinnati, Ohio, The Washroom.

The Cowles Detergent Co., Cleveland, Ohio, Scientific Washing.

British Launderers' Research Association, The Control of Laundry Operations.

U. S. Department of Agriculture, Farmers' Bulletin No. 1497, Methods and Equipment for Home Laundering.

Kessler, D. W., A Study of Problems Relating to the Maintenance of Interior Marble, B. S. Tech. Paper No. 350.

McGowan, F. R., Smither, F. W., and Schoffstall, C. W., Performance Tests of a Liquid Laundry Soap Used with Textile Materials, B. S. Tech. Paper No. 273.

Baker, E. M., and Schneidewind, Richard, Metal Cleansing with Alkaline Cleaning Solutions, Trans. Am. Electrochem. Soc.; 1924.

Mitchell, R. W. The Technology of Powdered Soap, Am. Perfumer and Essential Oil Review; May, 1927.

Specifications, See Section XII of this circular.

\section{DRY CLEANING}

\section{NATURE AND APPLICATION OF DRY CLEANING}

"Dry cleaning," so called, is performed in a variety of ways, in all of which, however, the fabrics are immersed in a fluid other than water. It is also known as "French cleaning" and "chemical cleaning." In this process most of the oily or fatty substances that hold dirt or "soiling matter" on or in fabrics is dissolved by the drycleaning fluid or solvent so that the dirt may be readily removed by mechanical agitation. Dry-cleaning soaps, and at times certain special solvents, are mixed with the dry-cleaning solvent to serve as detergent aids. These are said to absorb the surface moisture on fabrics, permitting greater penetration of the solvent and the "wetting" of the fabric by it.

Fabrics adaptable to the dry-cleaning process do not, when immersed in the common dry-cleaning solvents, shrink, lose shape or finish, etc., as is frequently the case in "wet cleaning"-washing in water. Therefore, fabrics that are wet or hold excessive moisture should be brought to an air dry condition before subjecting them to the dry-cleaning process. The ordinary laundry type washer is generally used in the dry-cleaning plants. In the dry-cleaning process the rinses are made with clear solvent, without any additions, in order to remove all traces of soaps and loose soiling matter that may remain in the goods after the cleansing or "washing" operation. Most of the excess of solvent is then removed ("extracted") by centrifuging, and finally the last portion of the solvent is evaporated by the use of air at about $150^{\circ} \mathrm{F}$. in a drying tumbler, or at lower temperatures in deodorizing cabinets or rooms, dependent upon the type of materials being: processed. (See references at end of this section for publications describing dry-cleaning processes, equipment, etc.)

The nature of the fibers and the a'yes, condition of the fabric, furs, gloves, etc., character of soiling matter, sizing materials, weighting materials, etc., must be carefully considered in using dry-cleaning solvents and detergent aids. Drying temperatures, finish, and condition of the cleaned article, etc., must also be considered. Certain textiles are not adapted to dry cleaning; for example, rubber goods or rubberized fabric, articles fastened with marine glue, fabrics dyed with oil-soluble dyes or coloring matter, artificial flowers, certain leather and fur trimmings, etc. 


\section{DRY-CLEANING SOLVENTS}

Water-free solvents that have been used in cry cleaning include gasoline, naphtha, benzene (benzol), ether, chloroform, carbon tetrachloride, carbon disulphide, and turpentine. Dry-cleaning solvents should be chemically inert to textile fibers and to the dyes that may be used on them; however, some basic dyes may be affected by practically all of the common dry-cleaning solvents. They should not tarnish or corrode metal buttons or trimmings. Such solvents should not be injurious to the workmen (benzol and carbon disulphide vapors are especially toxic when inhaled), should have a fairly high flash point and initial boiling point to reduce the fire hazard and losses by evaporation, should have a low enough end point (final boiling point) to permit the removal of the last traces of the solvent in drying, should be free from suspended matter, water, and colored or odorous constituents. Until recently the solvent in most general use in this country was ordinary motor gasoline, as sold at the automobile filling stations. In order to reduce the fire hazard and to obtain a solvent free from "heary ends" and sulphur compounds and low in unsaturated compounds, the National Association of Dyers and Cleaners of the United States and Canada, through research associateships at the Mellon Institute of Industrial Research and at the Bureau of Standards, has developed a special petroleum distillate for use as a dry-cleaning solvent. This distillate, known in the dry-cleaning and petroleum industries as "Stoddard solvent," has a minimum flash point of $100^{\circ} \mathrm{F}$. in a closed cup tester. Reference to a specification for this solvent will be found in the appendix.

\section{DRY-CLEANING SOAPS}

A dry-cleaning soap should be capable of cleansing all kinds of textile materials without any injurious effect on the fibers or colors. It should be readily miscible with the dry-cleaning solvent; it should leave no deposit on the goods nor impart an odor. The dry-cleaning soaps, also known as "benzine soaps," in general use in this country are soaps in which the fatty acid base has not been completely saponified by alkali. They are often prepared in a gasoline vehicle, and are sometimes referred to as "superfatted soaps"; they are only partly soluble in the dry-cleaning solvent (gasoline or "Stoddard solvent"), but are fairly readily dispersed or uniformly distributed in such a medium. The completely saponified or "wet washing" soaps are practically insoluble in such solvent. However, an American manufacturer has recently put on the market the material known as "commercial triethanolamine," which is said to be a mixture consisting of approximately 70 to 75 per cent triethanolamine, 20 to 25 per cent diethanolamine, and 0.5 per cent monoethanolamine. It is reported that this product combines with fatty acids producing soaps that are soluble both in water and in dry-cleaning solvents. The fatty base in dry-cleaning soaps is usually oleic acid and the alkali used in making the soap is usually caustic potash, caustic soda, or a mixture of the two. Ammonia is frequently used in making dry-cleaning soaps, forming an acid ammonium oleate. However, owing to the probable action of ammonia on some equipment, on certain types of dyes, and on some stains, the National Association of Dyers and Cleaners have advocated ammonia-free soaps. Dry- 
cleaning soaps are made up of various consistencies to meet the personal preferences of the users. To attain this the soap manufacturers modify the fatty base by adding stearic acid or other fatty matter and incorporating various solvents besides gasoline, such as alcohol, benzene, toluene, xylene, acetone, carbon tetrachloride, etc.

The optimum temperature for dry cleaning the average type of goods is stated to be $70^{\circ} \mathrm{F}$. However, with very badly soiled goods, such as greasy overalls, a higher temperature may be used. The soup manufacturers, therefore, put out dry-cleaning soaps for use at different temperatures in the cleaning operations. Special stainremoring soaps are also on the market; they generally contain special solvents or mixtures of solvents. Certain stain-removing soaps, known as "prespotting" soaps and "hand-brushing" soaps, are being widely used to eliminate a large number of "spotting" operations. These "selective" or special soaps may contain various volatile solvents incorporated with the dry-cleaning soap base, such as chloroform, carbon tetrachloride, ethyl acetate, amyl or butyl alcohol, amyl acetate, ethylene dichloride, ether, trichloroethylene, pyridine, phenol, cresol, hydrogenated phenols ("hexalin," etc.), etc. These "prespotting" or "hand-brushing" soaps contain a comparatively large amount of water, but are practically "soluble" in the dry-cleaning solvent, the "hexalin" or other added substance acting as a "carrier" for the water. The soiled garment may be thoroughly "wetted" with clean dry-cleaning solvent, brushed with the "prespotting" soap (or the soap applied with a spatula), and then put through the usual cleaning process. However, in modern practice the garment is first rinsed in clear solvent, then given a treatment or wash with the dry-cleaning solvent containing ordinary benzine soap, followed in many cases by treatment with the solvent containing the so-called "prespotting" soap. A recent development is the use of a high concentration of ordinary benzine soap in cleaning certain types of goods. Some stains may require "spotting" before dry cleaning.

The treatment with "prespotting" soap removes most of the ordinary spots or stains and results in faster work and more economical operation, as the older method required hand "spotting" of all spots or stains not removed by the solvent containing ordinary dry-cleaning soap. For cleaning moderately soiled garments, the use of a simple dry-cleaning soap in the washer is satisfactory. Apparently, the use of complex mixtures is not necessary, except as "prespotters."

A simple dry-cleaning soap may be made by dissolving 1 pound of caustic soda in 2 quarts of soft water, and pouring the solution in a small stream, with constant stirring, into a mixture of 6 quarts of cleic acid and 8 quarts of ordinary gasoline; finally, stir the whole mixture for 15 to 20 minutes. Caustic potash might be substituted for the caustic soda. In the dry-cleaning plant a stock solution is mase by dissolving a definite quantity of the dry-cleaning soap in a definite volume of the dry-cleaning solvent. This stock solution is then added to the washer in quantities determined by the capacity of the washer, size of load, type of goods, degree and character of soiling, etc.

Some dry-cleaning soaps are made by dissolving the caustic alkali in alcohol and adding the solution to oleic acid. Special dry-cleaning soaps are prepared for specific purposes, such as leather glove clean- 
ing, hand brushing, etc. Rugs and carpets, although frequently dry cleaned, are probably more often wet cleaned. In the latter case a soap stock may be made as follows: Cover 2 pounds of a neutral low-titer soap (wet washing soap) and one-half pound of trisodium phosphate with soft water, heat with direct steam until a clear solution is obtained, shut off steam, and add sufficient cold, soft water, with constant stirring, to make a total volume of $12 \frac{1}{2}$ gallons. Work at the Bureau of Standards by the research associates of the National Association of Dyers and Cleaners has shown that when furs are to be dry cleaned the addition of a small percentage of paraffin to the dry-cleaning solvent (a stock solution should be kept separately from the solvent used in the washers or held in the storage system), improves the appearance and pliability of furs. Recommended standards of practice for dry cleaning furs, when such a process is required, have been formulated and published in Bureau of Standards Technologic Paper No. 360.

\section{THE DRY-CLEANING PROCESS}

The National Association Institute of Dyeing and Cleaning (Inc.), has furnished the following information on the procedures used in its model plant:

(a) Method for Cleaning Heavy Woolens.-(1) Inspect the garments for defects and then sort according to color into whites, light colors, medium colors, and dark colors. (2) Fill the inner cylinder of the dry-cleaning washer one-third full with clean, new, or purified (reclaimed) "Stoddard" solvent. (3) Load the garments into the washer until the inner cylinder is not more than one-half full after complete settling of the garments. (4) Start the machine and give the load a 5-minute "break" (agitation with the solvent to remove soluble and loosened dirt, corresponds to a soaking process), using the continuous flow system. If the latter is not used, two batch rinses are made. (5) Pump new or purified solvent into the machine until the total load again fills the inner cylinder one-half full, add 1 pound of benzine soap stock solution (made by mixing 1 pound of benzine soap for each gallon of "Stoddard" solvent) per 100 gallons of solvent, and run the machine for at least 10 minutes. (6) Then turn on the continuous flow and let run for about 10 minutes to remove all of the benzine soap. (7) With the washer one-half filled with fresh solvent and the garments add 2 quarts of alcoholic or other special type of dry-cleaning soap-stock solution for every 100 gallons of solvent, and run the machine for about 10 minutes. (8) Then turn on the continous flow and run until soap is removed; this usually requires about 10 minutes. (9) Insert a drain board into the washer and turn the latter one-half over, allowing the solvent to drain off. (10) Place the garments in a centrifugal extractor and run for 2 minutes after its maximum speed has been attained. (11) Sort the garments, place those which will withstand tumbling in the tumbler, and subject them to a good circulation of fresh air at a temperature not above $160^{\circ} \mathrm{F}$. Sterm is also injected for the major portion of the tumbling operation to eliminate static electricity and to free the materials of lint. Materials that will not withstand tumbling are hung up in a good circulation of fresh, clean air in a drying room or cabinet, the temperature of which does not exceed $120^{\circ} \mathrm{F}$., and allowed to deodorize completely. 
(b) Method for Cleaning Fancy Wool, Silk, and Rayon.(1) Inspect the garments for defects and sort according to color. (2) Fill the inner cylinder of the dry-cleaning washer one-third full with clean, new or purified "Stoddard" solvent. (3) Load the garments into the washer until the inner cylinder is not more than one-half full after the garments have settled. (4) Start the machine and give the load a 5-minute "break" with the continuous flow in operation. (5) Transfer the goods to a washer containing a concentrated soap solution (made by mixing 1 pound of benzine soap for each 2 gallons of "Stoddard" solvent) and run the machine for at least 20 minutes. (6) Return the goods to the first washer and rinse for 15 to 20 minutes with the continuous flow, or make at least two batch rinses. If tests now indicate the presence of soap, rinsing is continued with clear solvent until the goods are soap free. (7) Drain the goods on a board in the washer and extract them in a centrifugal machine, stopping the machine when it has reached its maximum speed. (8) Hang the extracted goods in a drying room or cabinet in a good circulation of fresh, clean air at a temperature not exceeding $120^{\circ} \mathrm{F}$. Should any spots or stained areas remain that appear to the experienced operator as removable by prespotting methods, the garments are returned to the dry-cleaning room, saturated with "Stoddard" solvent, and treated with a special prespotting soap.

Laces, tulles, and other delicate materials may either be cleaned by hand in a concentrated soap solution, or, if they will withstand the mechanical action of the washer, are put into net cotton bags and run in the washer.

Velvet garments should be turned inside out and pinned along the bottom to prevent their edges rolling during the cleaning process.

The "concentrated-soap-solution" method has the following advantages: Better cleaning, less spotting, prespotting, and naphtha brushing, saves time, costs less in the long run, produces brighter colors, and reduces wet cleaning.

The concentrated soap solution is used for successive loads of garments until too dirty for further use. The "life" of a batch will probably average about 15 loads.

(c) Méthod for Cleaning Cotton and Linen.-Cotton and linen fabrics are seldom dry cleaned, unless combined with woolens or silks or used in heavy draperies. In such cases they are handled in the same manner as silks and rayons.

\section{STAIN REMOVAL OR "SPOTTING"}

Successful spotting requires the most skillful and experienced employees in the dry-cleaning industry. In the modern dry-cleaning plant, spotting is carried out on specially designed and constructed porcelain-topped boards, called "spotting boards." The spotter inspects fabrics for stains and defects, and decides upon and applies the best and most economical procedure to follow. He must be familiar with textile fibers, sizing materials, the various dyestuffs used, the various stains or spots that may be encountered, the reagents or chemicals to be used and their action on fibers and dyes. He must know that certain stains are changed and become practically insoluble in reagents, or "set," if carried through the dry-cleaning process without preliminary treatment, and that stains due to linseed oil, paints, varnishes, etc., are best treated before dry cleaning. 
Spotting reagents should be used in such sequence as to avoid the "setting" or fixing of stains in fabrics, to reduce the number of reagents required to the minimum, to prevent injury to the fabric, and to leave the dye undisturbed in the fabric.

Spotting should be done either before or after dry cleaning, to aroid if possible, any wetting with water which would remore the sizing in many fabrics and increase the cleaning cost. In treating stains on colored goods the dye is frequently removed or changed by the stain-removing reagent. In such cases the spots are sometimes "touched up" or "filled in" by an appropriate dye properly applied, the so-called "spot dyeing." "The dye or color in extreme cases is frequently completely remored, or "stripped," and the fabric redyed.

Stains may be classified under rarious headings, such as corrosive and noncorrosive, and according to the effects produced by high temperature, atmospheric exposure, sunlight, bleaching agents, etc. Some stains may be of such a nature as to be practically nonremovable especially after haring become "set" or fixed in the fabric. The "tendering" of fabrics may be due to errors or mistakes of the manufacturer, the user, or the cleaner. Furthermore, there may be hidden damage to fabries before submission to the cleaner that may be manifested only after subjecting them to the various cleaning operations. The listing of the various reagents that may be used, the different types of stains that may be encountered, and methods of stain removal can not be covered in this circular. Such information, applying to dry-clesning plants and to home procedures, will be found in the references given at the end of this section, particularly United States Department of Agriculture Farmers' Bulletin No. 1474 on Stain Removal from Fabrics-Home Methods.

\section{FINISHING}

The object of finishing is to give the cleaned or dyed garments the required feel, luster, shape, and a good appearance in general. Owing to the wide variety of materials submitted to the dry cleaner, finishing has become a highly technical operation, which includes ironing, pressing, steaming, stretching, etc., and requires the use of many special pieces of equipment; for example, so-called pufi irons to finish gathers, ruffles, etc., special steam boards for velvets, special pressing machines for men's garments, special equipment for ties, hats, gloves, etc.

\section{RECLAMATION OF DRY-CLEANING SOLVENT}

In the dry-cleaning process the soiling matter remored from the garments is held in suspension by the dissolved dry-cleaning soap. The solvent becomes discolored and rancid or foul by decomposition products and soiling materials and is finally unsuited for use in the cleaning process. It is then purified and recovered. The time required for the solvent to become too foul for use depends upon a number of factors, such as the nature of the soiling materials encountered, the number of garments cleaned, the character of the solvent, ${ }^{6}$ soap, appliances, condition of storage, etc. The dry-cleaning industry of the United States uses about 30,000,000 gallons of solvent

${ }^{B}$ Dry-cleaning equipment in universal use is that in which the garments being cleaned are subjected to a continuous flow of new or purified sol vent, that is, soiled cleaning solvent is being discharged from the dry-cleaning washer and water-white solvent is admitted to the machine during the entire operation. 
per year in cleaning operations. Obviously, a rapid and economical process for the purification and recovery of used solvent is of vital interest to this industry.

Various processes of reclamation (also called purification and clarification) have been proposed. The following are probably the most widely used:

(a) Distillation Process.- In the distillation process there may be loss of solvent by incomplete condensation of the vapors, or by retention in the still residue (soiling matter, soap, etc.), the recovered solvent may not be as "sweet" as that purified by some of the other methods, and fuel consumption may be an adverse factor. With ordinary motor gasoline there would be a loss on account of the "heavy ends" which can not be distilled readily; such loss should be negligible with "Stoddard" solvent if the distillation is carried out under a partial vacuum.

(b) Alkali-Carbon Process. - In this process the dry-cleaning ("superfatted") soap and dissolved fatty matter are completely saponified, forming water-soluble soaps that are practically insoluble in the dry-cleaning solvent. These soaps precipitate and carry down with them much of the finely divided soiling matter held in suspension, leaving coloring matter in solution. Coloring matter, odors, and probably certain dissolved compounds are removed by intimately mixing the used dry-cleaning solvent with an activated carbon. ${ }^{7}$ The alkaline compounds generally used are trisodium phosphate, caustic soda, or sodium silicate. The used solvent may be treated with an aqueous solution of the alkali, the precipitated matter removed by settling or centrifuging, and the recovered solvent then treated with activated carbon. Or, the activated carbon may be mixed with a small amount of clean solvent and the mixture poured into a conebottom settiing tank; the alkaline compound is dissolved in water and the solution poured into the settling tank; the tank is filled with the dirty, used solvent and the mixture is agitated for 15 minutes by pumping (centrifugal pump) from the upper portion of the tank, the solvent being discharged back into the cone bottom of the tank. The mixture is allowed to stand until the reagents and impurities have settled out and the supernatant, purified solvent drawn of into storage tanks.

One charge of activated carbon and alkali may be used for several lots of used solvent, depending upon the condition of the solvent being purified, amounts used, etc. After a "purifying charge" has become too foul for further use, the dry-cleaning solvent held by it may be recovered by treating the mixture with an equal volume of water and letting stand a few hours for the water, reagents, and impurities to settle, leaving the dry-cleaning solvent as the upper layer. In the alkali-carbon process, direct steam or excessive agitation may cause emulsions that are difficult to handle. If trisodium phosphate is used the temperature should be maintained between $60^{\circ}$ and $80^{\circ} \mathrm{F}$. This process as above outlined is for batch treatment of the dirty, used solvent pumped from underground storage tanks, but it can also be readily applied in the continuous systems designed for the use of caustic-alkali solutions alone.

7 Activated carbon is carbon which has been treated chemically and otherwise in order to increase its decolorizing and adsorptive properties. 
(c) Alkali-Continuous Process.- In this process the dirty solvent is pumped from the washer through an aqueous solution of caustic soda containing activated carbon, then washed with water, filtered, and returned to the washer. The dirty solvent is often run from the washer through a centrifugal clarifier, then treated with the alkali solution, washed, passed through the clarifier or "purifier," filtered, and returned to the washer. A continuous system must handle many times the rolume of solvent that would be handled by a batch system cleaning the same quantities of goods, and, therefore, the cost of treatment must be low. In the continuous processes, the color may not be entirely eliminated from the solvent, but it is markedly reduced.

(d) Acid-Base-Continuous Process. - In this process the dirty solvent is run from the washer through a centrifugal clarifier; a suitable amount of the clear, dark solvent from the clarifier is treated with concentrated sulphuric acid and then with a neutralizing solution (caustic soda). The treated, decolorized solvent is then returned to the main stream, passing back through the clarifier (to remove the last traces of caustic soda) back to the washer.

(e) Filtration.-Direct or gravity filtration of the dirty solvent through fuller's earth, sand, or charcoal is difficult and time consuming owing to the slimy nature of the solids to be removed. The probable loss of solvent by evaporation and otherwise is also a factor that has caused the practical abandonment of this process in this country.

A recent development in the application of the chemical processes (such as the alkali carbon, alkali continuous, etc.) is the passage of the solvent, containing alkali, activated carbon, diatomaceous earth or other filter aid, under pressure through filters, the clear, "purified" solvent returning to the washer or a storage vessel.

(f) Processes Using Special Reagents.-Mixtures of caustic soda, chip soap, soda ash, and other materials have been used in the purification of dirty solvent both by batch and continuous treatments. Good results have been reported in certain plants using a commercial product consisting of a mixture of trisodium phosphate, soda ash, colloidal clay, colloidal cellulosic matter, and soap. The dirty solvent is run from the washer into a tank containing the purifying agent and trisodium phosphate in water; after agitation, the solvent flows into a tank containing water and from this into a series of tanks in tandem. The suspended matter and aqueous solution settle out in the series (mainly in the first tank). The reclaimed solvent finally passes through a cloth filter to insure removal of all solid matter, and is then returned to the washer. One charge of the reagents will handle a large rolume of dirty solvent, the amount depending upon the condition of solvent and the quantities of materials used.

\section{ELIMINATICN OF STATIC ELECTRICITY}

Ignition of the dry-cleaning solvent by static electric sparks produced by the rubbing of textile fabrics in the solvent has been the cause of many fires with resulting loss of life and property. It was noted that such spontaneous firing generally occurred during the cold months, when the relatire humidity was low, and in the rinsing operations. In 1893 Richter reported that a small amount of magnesium oleate dissolved in benzine prevented electric excitation of the 
solvent. It was later found that the ordinary dry-cleaning soaps acted similarly and, hence, the comparative freedom from this hazard in the washer. It was then suggested that a very small amount of the soap be dissolved in the rinsing solution, but this would leave soap in the goods. To reduce this fire hazard, the National Association of Dyers and Cleaners developed the "Stoddard solvent" referred to above. This association has also shown that properly "humidified" garments would practically eliminate the danger, and has recommended that a relative humidity of 70 per cent be maintained in the receiving department. The time required for the handling of the garments in this department is sufficient to permit the absorption of sufficient moisture to prevent the production of static sparks during the subsequent cleaning process. Line shafting and machines should be properly grounded. This and other precautions are specified in the safety codes of the fire-protection organizations.

\section{REFERENCES}

Hubbard, C. C., The Instructor in Garment Cleaning, National Association of Dyers and Cleaners of the United States and Canada, Silver Spring, Md.

Hubbard, C. C., Dry-Cleaning and Redyeing Handbook, C. C. Hubbard, Silver Spring, Md.

Cooley, Warren K., Practical Science for the Dry-cleaning Industry, National Association of Dyers and Cleaners of the United States and Canada, Silver Spring, Md.

Farrell, Frank J., Dyeing and Cleaning, D. Van Nostrand Co.

Brannt, William T., and Gray, J. B., Practical Dry Cleaner, Scourer, and Garment Dyer, Henry Carey Baird \& Co.

Owen, F. A., and Standage, H. C., The Dyeing and Cleaning of Textile Fabrics, John Wiley \& Sons.

Denney, Roy, Denney's Practical Guide to Cleaning and Spotting. Dowst Bros. Co., Chicago, Ill.

Pawlie, E., Practical Handbook of Garment Dyeing and Cleaning, M. M. Frank, Philadelphia, Pa.

Laundryowners' National Association, La Salle, Ill., The Conservation of Textiles.

U. S. Department of Agriculture, Farmers' Bulletin No. 1474, Stain Removal from Fabrics. Home Methods.

Hubbard, C. C., Reclamation of Gasoline Used in Dry Cleaning, B. S. Tech. Paper No. 280.

Flowers, A. E., McBerty, F. H., and Dietrich, M. A., Chemical Process for Rerefining and Decolorizing Dry-Cleaners' Solvent by Continuous Automatic Methods, Ind. Eng. Chem., 19, pp. 868-873; 1927.

Hinchley, J. W., A Process for the Treatment of Solvents Used in Dry Cleaning, J. Soc. Chem. Ind., 幽4, pp. 117-123; 1925.

Hubbard, C. C., Goldman, M. H., and Schoffstall, C. W., Effect of Dry Cleaning on Silks, B. S. Tech. Paper No. 322.

Goldman, M. H., and Hubbard, C. C., Cleaning of Fur and Leather Garments, B. S. Tech. Paper No. 360.

Specifications: See Section XII of this circular.

\section{POLISHES}

\section{FURNITURE AND AUTOMOBILE POLISH}

Polishes that are suitable for furniture can be used on automobiles also, provided the finishes are of the same type and in practically the same condition. Varnish, ordinary enamel, cellulose ester (lacquer), and baked enamel finishes are the surfaces that are generally encountered. There are differences in the hardness of finishes, the fastness of colors, and the resistance to solvents and abrasives. 
Furniture and automobile polishes. should remove dirt and grease readily from the surfaces, restore their luster, and be nearly completely removable, so as not to leave the surface in such condition as to hold dust or to leave any objectionable odor. Such polishes should contain no alkali or alkaline compound that will attack finishes; emulsions should be stable or constant; the nature and amount of solvents and oils used should be duly considered; for example, alcohol, benzol, and other solvents may seriously attack cellulose ester (lacquer) finishes. Nitrobenzene (nitrobenzol or "oil of mirbane") should not be used to impart odor to polishes, as it is poisonous.

(a) Orl Polishes.-Most of the straight oil polishes consist wholly, or mainly, of a mineral oil. Mineral oil polishes are cheap, do not oxidize, and give a glossy polish if rubbed off thoroughly. Mixtures of mineral oil (paraffin oil) and linseed oil, usually with other ingredients, are also used. Linseed oil is used as a component of many polishes for varnished surfaces. Polishes containing it or other drying oil should be rubbed off thoroughly from the surface being polished. Cloths used for applying the polish and rubbing down the surface should be kept in tightly closed tin containers on account of the danger of spontaneous combustion.

(b) Wax Polishes are made in paste and liquid form. Some of the emulsion polishes contain some wax, usually beeswax. Although beeswax is used in many polishes, the harder waxes with higher melting points, such as carnauba wax, are to be preferred. Some of the wax polishes soften at fairly low temperatures and may whiten by long contact with water. Polishes showing these properties would be more satisfactory on furniture than on automobiles.

(c) Special Mixtures.-Most of the commercial polishes probably fall under this heading. These polishes may consist of mixtures of oils, waxes, volatile solvents, abrasives, acetic acid (or vinegar), antimony trichloride ("butter of antimony"), .camphor, drier, etc. Alkanet root and oil-soluble dyes are sometimes used to impart a red or other color to such polishes. Essential oils are sometimes added to impart a pleasant odor or to mask the odor of certain ingredients. Many of these polishes are emulsions. The abrasive used in making a polish, or a combined polish and surface cleanser, should be selected with care in order not to scratch or otherwise mar the finishes on which the polish may be used. Pumice, tripoli, diatomaceous earth (infusorial earth, tripolite, diatomite, kieselguhr, etc.), chalk, and silica are some of the commonly used abrasives. The abrasive should be a uniform and very finely powdered product. Very fine abrasives are apparently used in small amounts in the preparation of some polishes for cellulose ester (lacquer) finishes. The polishes for varnish and ordinary enamel coatings as a rule do not contain any abrasive, as these finishes are easily scratched.

(d) Formulas.- The Bureau of Standards has not developed formulas for furniture and automobile polishes, but the following: are said to be satisfactory for use on the ordinary varnish and enamel finishes. In making up polishes care should be taken to have no flames around as gasoline, turpentine, petroleum spirits, etc., are highly flammable.

1. Formula developed by the Bureau of Construction and Repair, Navy Department, and recommended by the Federal Specifications 
Board for the use of the various departments and independent establishments of the Government. For use on varnish and paint coatings on wood.

$\begin{array}{lr}\text { Material: } & \text { Pounds } \\ \text { Cider vinegar } & \\ \text { Petroleum spirits } & \\ \text { Turpentine } & \\ \text { Denatured alcohol } & \\ \text { Boiled linseed oil } & \\ \text { Raw linseed oil } & \end{array}$

The quantities given above are sufficient to make 100 gallons of the polish. Using ounces instead of pounds will make 61/4 gallons. Polishes containing acetic acid (vinegar) should not be put in metal containers.

2.

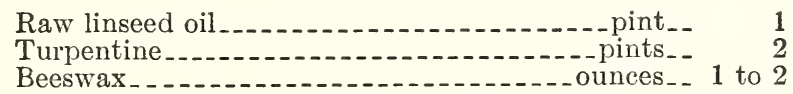

Dissolve the beeswax in the linseed oil by heating slightly, remove from the source of heat, add the turpentine and mix. Shake well before applying.

3. A straight mineral oil, neutral in reaction; such as transformer oil or paraffin oil.

4. Mix 1 pint of linseed oil, 3 pints of water, and 1 pint of denatured alcohol. Shake well before applying.

5. Emulsion polishes similar to the following have been used on cellulose ester (lacquer) finishes:

Material:

Parts (by weight)

Mineral spirits or gasoline

A mixture of beeswax and carnauba wax

Finely-powdered diatomaceous earth or tripoli (325 mesh or finer) -

Water$44-44.5$

Neutral soap

Dissolve the waxes in the gasoline by warming in hot water, add the abrasive to this solution and mix by stirring or shaking; dissolve the soap in the water; add the soap solution to the gasoline mixture, and shake thoroughly. The soap solution should be just warm enough to remain liquid so that the gasoline will not boil out of the vessel. Shake well before applying. This type of polish should be used with care to avoid marring the finish by too vigorous rubbing. Polishes which contain no abrasive are also in use for cellulose ester coatings. The formula listed, or a modification of it, might be tried, omitting the diatomaceous earth or tripoli.

\section{METAL POLISH}

Although polishing powders are in use, metal polishes usually consist of some abrasive material in suspension in a liquid or semiliquid vehicle. The principal difference in composition between the paste and liquid polishes is in the vehicle employed. The abrasive materials should possess such hardness, fineness, and shape of particles as will best accomplish the desired polishing without scratching. Metal polishes should not contain mineral acids or other materials that may have an injurious effect on metals. They should not contain cyanides or nitrobenzene, and should be free from disagreeable odor. Obvi- 
ously, a softer abrasive, such as rouge (oxide of iron) or precipitated chalk (calcium carbonate), is required for highly polished surfaces than for relatively dull surfaces, such as kitchen utensils, for which various siliceous materials are generally employed. The vehicle in the pastes is usually a petroleum product (heavy mineral oil, vaseline, paraffin, etc.) or a fatty product (stearin, tallow, stearic acid, oleic acid, etc.) or both, to which soap and other materials (for example, oxalic acid, cream of tartar, etc.) are sometimes added. Pine oil is also a common and valuable solvent in soap-base metal polishes. It gives body and helps hold the abrasive matter in suspension. The nonflammable liquid polishes usually have as a vehicle water containing soap with kerosene and ammonia or a mixture of kerosene or other petroleum distillate with sufficient carbon tetrachloride to render the mixture nonfiammable. The flammable polishes usually contain gasoline, kerosene, or other petroleum distillate. As a rule, the liquid polishes are more efficient where much tarnish is to be removed, but they should be used with care if they contain flammable ingredients. The paste and liquid polishes sometimes contain essential oils to mask the odor of certain ingredients.

Polishing powders may be a single substance, such as rouge or chalk, or a mixture of various abrasives with or without added materials. On plated ware, such as nickel plate, silver plate, etc., only the mildest abrasives should be employed because of the thin coatings commonly used. Precipitated chalk, rouge, powdered talc, or other finely-powdered abrasive, free from hard or gritty particles, would probably be the safest abrasive to use. The "electrolytic cleaning" of silver is described and discussed in papers by members of the Bureau of Standards, published in Metal Industry (New York), January, March, April, and June, 1924.

Groggins and Scholl have recommended orthodichlorobenzene as a cleaner for metals and as an ingredient of metal cleaners. A paste prepared by mixing 1 part of precipitated chalk with 5 parts of orthodichlorobenzene and applied with a cloth is said to be very effective for cleaning and polishing silverware and other metals in the home and for removing rain spots from nickel-plated automobile radiator shells. The compound may be mixed with other abrasives as absorbents to yield polishing pastes. Table utensils polished with such products should be dipped into boiling water before they are used again.

\section{FLOOR POLISH}

Floor polishes may be roughly classified as pastes (the so-called floor waxes) and liquids (suspensions or emulsions), frequently called "liquid floor waxes." The former usually consist of beeswax, carnauba wax, ceresin, or a mixture of these together with turpentine, volatile mineral oil, ammonia, etc., to produce the desired consistency. The liquid polishes, which are easier of application, usually contain the same materials as the pastes but have a larger proportion of turpentine or mineral oil. In addition, they may contain water, limewater, potassium carbonate, etc.

The following formulas, given in Bureau of Standards Circular No. 70, furnish good floor waxes or paste polishes. In making either of the following waxes be very careful to heat only by setting the vessel containing the waxes in hot water and to have no flames in the room, since both gasoline and turpentine are very flammable. 


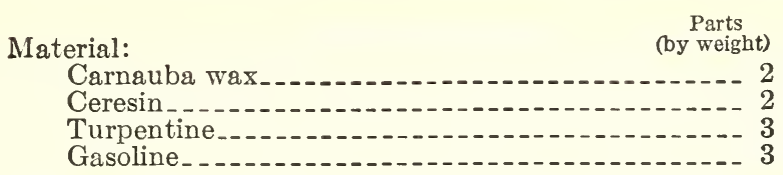

Melt the waxes by heating in a vessel placed in hot water, add the turpentine and gasoline and cool the mixture as rapidly as possible, while vigorously stirring to produce a smooth creamy wax.

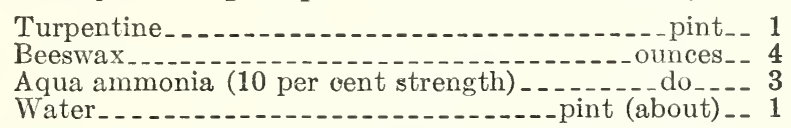

Mix the beeswax and turpentine and heat them by placing the vessel in hot water until the beeswax dissolves. Remove the mixture from the source of heat, add the ammonia and the water, and stir vigorously until the mass becomes creamy. This wax should be applied lightly on varnished or shellacked floors and any excess wiped off at once, as the ammonia may attack the varnish or shellac. When this wax is used on unfinished oak fiooring, the ammonia may cause a slight darkening of the wood.

Floor wax should be applied in very thin coats and thoroughly rubbed with a heavy waxing brush or a heavy block wrapped in burlap or carpet. In preparing a new or refinished floor for waxing it is common practice to apply a coat of shellac varnish or other quick-drying varnish before waxing. If this is done, it is better to have a very thin coating of shellac as thicker coatings are apt in time to crack or peel, which will necessitate complete refinishing. The wax can be applied directly to close-grained woods such as maple or pine, or to such open-grained wood as oak, if a silicate filler is first applied. This treatment requires more waxing, and, therefore, more labor in the original job, but the finish is likely to be more durable. However, floors finished in this way will probably darken more with time than if the wax is applied over a thin coat of shellac.

\section{GLASS POLISH}

Polishes for glass are generally powders or pastes. Precipitated chalk, calcined magnesia, crocus or rouge (iron oxide), "putty powder" (tin oxide), and fine siliceous materials are the abrasives usually employed. In addition, they frequently contain soap, sodium carbonate, trisodium phosphate, ammonium compounds (or ammonia), for the purpose of removing grease, etc.

\section{STOVE POLISH}

Stove polishes may be obtained as powders, so-called liquids, pastes, and sticks or cakes. Graphite is usually the basic ingredient. Finely powdered graphite may be used directly as a stove polish after mixing with a little water. Lampblack, carbon black, and bone black are sometimes added to deepen the color, but these forms of carbon are more readily burned off than graphite. Nigrosine (a black aniline dye) has also been used to deepen the color of such polishes. Stove polishes may contain, in addition to graphite and other forms of carbon, such materials as copperas (ferrous sulphate), soap, "water glass" (sodium silicate), waxes, gums, sugar, glycerin, water, oils, turpentine, etc. Turpen tine or o ther readily flammable liquids should not be used in such polishes. The liquid polishes are generally of two types: (a) Graphite 
suspended in a water solution of sodium silicate, soap, etc., and (b) a suspension of graphite in a petroleum distillate (oil) mixture, or such a a mixture with the addition of carbon tetrachloride to render it nonflammable.

\section{SHOE POLISH}

The ordinary black shoe polishes generally contain wax (beeswax or carnauba wax), nigrosine (a black dye), sodium or potassium carbonate solution, soap, turpentine, etc. After the wax has been emulsified by boiling in the soda (or potash) solution (a solution of borax may also be used), the emulsion is mixed with a hot aqueous solution of ordinary laundry soap and sufficient nigrosine to give the desired depth of color. This cools to a soft paste. If the liquid form is desired, a good grade of castile soap (pure olive oil-soda soap) or a soft (potash) soap may be substituted for the laundry soap. Another method is to dissolve carnauba wax or candelilla wax or a mixture of the two with beeswax and ceresin or paraffin in hot turpentine and mix with very finely pulverized bone charcoal. Tallow, lard, neat'sfoot oil, spermaceti, rosin, gums, and various other materials have been used in making shoe polishes.

Brown shoe polishes consist of such substances as soft soap, wax, glycerine, linseed oil, turpentine, shellac, etc., to which is added some dye; for instance, annatto, aniline yellow, etc. The following formulas and information have been furnished by a manufacturer:

1. Cleaner for such leathers as Russia calf, black or tan vici, and white kid.-Dissolve 8 ounces of granulated castile soap in 1 gallon of hot, soft water, add $3 \frac{1}{2}$ gallons of warm, soit water, cool, add 16 ounces of ethyl ether, and mix.

2. Patent leather cleaner.-Dissolve 4 ounces of granulated castile soap in 1 gallon of hot, soft water, cool, add 2 quarts of denatured alcohol, and then 16 ounces of ammonia water (specific gravity 0.90), mix.

3. Water polish or dressing.-Dissolve 1 part by weight of castile soap in 16 parts of clean, soit water, and heat the solution to boiling. Add to the boiling soap solution with constant stirring 4 parts by weight of a good grade of carnauba wax or other suitable wax, as Japan wax or beeswax (cut into small pieces). When a smooth homogeneous emulsion is obtained, cool to a temperature of $135^{\circ} \mathrm{F}$. by quickly adding, with constant stirring, the necessary quantity of cold water. (This should take about 14 to 16 parts more of water.) Let cool, filter through cheesecloth, and stir in about 0.5 per cent of formaldehyde as a preservative. The product so obtained should be of the color and consistency of cream. A thicker or thinner product may be made by decreasing or increasing the quantity of water used, taking care to maintain the given ratio between soap and wax. The polish may be colored by thoroughly stirring in a strong solution of a suitable water-soluble dye; for example, for a black polish, add a solution of 1 part of nigrosine dissolved in 12 parts of water.

4. Oil polishes.-Many of the formulas for an oil polish, such as the turpentine paste polishes, do not include soap at all, being made up of a wax base and a small amount of other materials with about 75 per cent of turpentine. Some of the firm paste polishes are made with a small amount of soap, beeswax, ceresin, and carnauba wax, with about 75 per cent of turpentine. 


\section{POLISHING CLOTH}

Cloths used for polishing furniture may be of cotton, wool, or silk. Some firms use cheesecloth and others use a wool cloth made specially for the purpose. Cheesecloth is probably the easiest to obtain since it is not made specially for polishing, and is the most economical. Wool and silk cloths are more expensive and when made for polishing furniture are usually woven so as to be soft and nonabrasive.

Polishing cloths or rags intended primarily for use on metals usually consist of woolen fabrics which have been saturated with fatty oil, mineral oil, or paraffin, or mixtures of these, containing in suspension a very finely powdered abrasive, such as tripoli or infusorial earth. Fatty acids have been used with paraffin in the preparation of such cloths, but may cause corrosion on some metals if a film of the acid remains. Muslin rags are also in use. Suspensions of tripoli (or other abrasive) in soap solutions, or mixtures of soap solutions, pine oil, ammonia, etc., have also been used for preparing polishing cloths. Some of these mixtures are colored with dyes and may contain a little essential oil. A polishing cloth might be prepared as follows: Dissolve a fatty oil (such as cottonseed oil), mineral oil (transformer oil or paraffin oil), or paraffin in gasoline, add the abrasive and mix thoroughly, pass the cloth through the suspension, and then stretch the cloth and allow to dry in this condition. If a vegetable oil (linseed, cottonseed, etc.) is used on wool, dry in a good circulation of air in a cool place not exposed to direct sunlight, in order to avoid danger of spontaneous combustion.

\section{DUST CLOTH, OILED}

These cloths are commonly referred to as "dust-less dust cloths." Such cloths may be made by saturating a fabric with kerosene, hanging $u$ to allow the more volatile part to evaporate, and then rubbing the oiled cloth on a wooden surface until it no longer streaks. These cloths may also be made by saturating them with a gasoline solution of paraffin, paraffin oil, linseed oil, or rapeseed oil, or a mixture of these, wringing out, and drying at room temperature. Sometimes essential oils or certain resins are added to the impregnating mixture.

\section{REFERENCES}

Scientific American Cyclopedia of Formulas. Munn \& Co. (Inc.), New York, N. Y.

Henley's Twentieth Century Book of Recipes, Formulas, and Processes. N. W. Henley Publishing Co., New York, N. Y.

1,995 Paint Questions Answered. The Painters' Magazine, New York, N. Y.

U. S. Department of Agriculture Farmers' Bulletin No. 1219, Floors and Floor Coverings.

Kelly, A. Ashmun, The Expert Wood Finisher, Press of the Master Painter Publishing Co., Malvern, Pa.

Schmidt, Walter K., Problems of the Finishing Room, The Periodical Publishing Co., Grand Rapids, Mich.

Groggins, P. H., and Scholl, Walter, Ortho-dichlorobenzene-An Excellent Cleaner for Metals. Ind. Eng. Chem., 19, pp. 1029-1030; 1927.

Vinal, G. W., and Schramm, G. N., The Tarnishing and Detarnishing of Silver. Metal Industry (New York), January, March, April, and June, 1924 ("Electrolytic Cleaning" of Silver.)

Baker, E. M., and Schneidewind, Richard, Metal Cleansing with Alkaline Cleaning Solutions. Trans. Am. Electrochem. Soc.; 1924.

Wightman, George E., Furniture and Automobile Polishes. Soap, 3, No. 8, pp. $37-38 ; 1928$. 
Brunner, Richard, The Manufacture of Lubricants, Shoe Polishes, and Leather Dressings, D. Van Nostrand Co., New York, N. Y.

Donald, J. T., Shoe Polishes and Dressings. J. Soc. Chem. Ind., 82, p. 459; 1913.

Fleischman, Leo N., The Development of Wax Polishes, Soap, 5, No. 1, p. 97; No. 2, p. 99; 1929.

Specifications: See Section XII of this circular.

\section{SWEEPING COMPOUNDS}

Although there are many floor-sweeping compounds or preparations on the market made up of sawdust, sand, oil, coloring matter, disinfectant, etc., it is believed that in many cases fine, hardwood sawdust moistened with water at the time of use will prove satisfactory for this purpose. Crumpled, dampened bits of paper and moist tea leaves are sometimes scattered over floors prior to sweeping in order to hold dust.

The Bureau of Standards has not issued any formulas or specifications covering such preparations. However, the Treasury Department uses a compound made up according to the following formula:

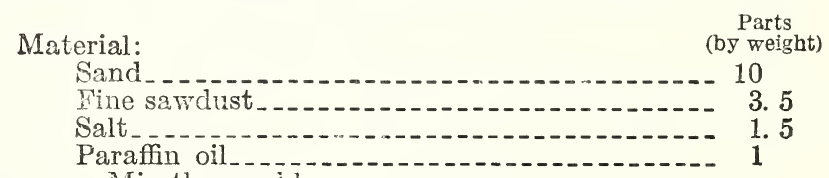

Mix thoroughily.

The Navy Department Specification No. 51-C-10 calls for a compound consisting of a uniform mixture of clean, fine sand and finely ground sawdust properly impregnated with a refined heavy mineral oil and water. Such a compound must show on analysis not more.than 20 per cent by weight of water, not less than 5 per cent of refined heavy mineral oil, not more than 50 per cent of clean sand, and the remainder finely ground sawdust.

Some of the commercial compounds are colored with iron oxide or other pigment and some contain naphthalene flakes, bran, paraffin wax, etc. Essential oils, such as oil of eucalyptus, oil of sassairas, etc., are frequently added to impart a pleasant odor to the compound or to mask any unpleasant odor of the ingredients used. Pine oil disinfectant, a small amount of creosote oil, and probably other materials, might be used as disinfectants.

If made up in small lots such compounds could probably be mixed satisfactorily by hand.

\section{REFERENCES}

Scientific American Cyclopedia of Formulas, Munn \& Co. (Inc.), New York, N. Y. Henley's Twentieth Century Book of Recipes, Formulas, and Processes, N. W. Henley Publishing Co., New York, N. Y.

U. 'S. Department of Agriculture Farmers' Bulletin No. 1219, Floors and Floor Coverings.

\section{WALLPAPER CLEANER}

The basic ingredient of many wall-paper cleaners is giuten, which may be supplied satisfactorily by the use of rye or wheat flour. The llour is made up into dough with water or with water containing 25 to 35 per cent of common salt. Preservatives may be added, such as sodium salicylate, sodium benzoate, borax, or certain essential oils. The latter are also added to impart a pleasant odor. Stale bread, 
usually rye bread, may be cut into slices and used as a wall-paper cleaner. Wheat bran (sewn up in a bag), pipeclay, and various other materials have also been used.

\section{REFERENCES}

1995 Paint Questions Answered, The Painters' Magazine, New York, N. Y. Scientific American Cyclopedia of Formulas, Munn \& Co. (Inc.), New York, N. Y.

\section{SPECIFICATIONS}

Large consumers, such as the various branches of the Government service, municipalities, etc., have for many years purchased various materials under definite specifications, an examination of which shows a great variety of requirements for the same kind of material.

Purchasing materials under specifications necessitates sampling and testing, which are costly operations; hence, it is advisable to purchase under specifications only when the amounts delivered are large. When the amount purchased are small, it is more economical to buy a brand desired than to incur the expense of testing a product offered at a low price.

It would be of distinct advantage to both manufacturers and consumers if one specification for any particular type of material could be generally used by a large number of consumers. Such a specification should secure a product suitable for the intended use, but, as far as possible, admit material of regular commercial makes. It should allow the greatest freedom, consistent with quality, in the selection of stock so that the manufacturer can take advantage of both varying market conditions and advances in technology and thus prevent, as far as possible, excessive prices due to temporary scarcity in any specific raw material. Methods of sampling and testing should be clearly defined and be made a part of the specification.

A method for reducing or eliminating the testing of deliveries, involving the certification by the manufacturer that the goods delivered by him comply with the requirements of certain specifications, is being introduced by the Bureau of Standards; and manufacturers desiring to do so are encouraged to use quality-guaranteeing labels for identifying such goods for the benefit of consumers who do not use specifications.

Below is given a list of specifications issued by the Federal Specifications Board for various materials covered by this circular. These specifications were prepared by technical committees appointed from the Government personnel in cooperation with the manufacturers of the materials involved. In the case of the soap specifications, the conflicting and divergent statements contained in the replies of the various manufacturers made it apparent that the matter could be best handled by a technical committee representing the manufacturers. The manufacturers were requested to designate such a committee to confer with a technical committee appointed by the Federal Specifications Board for the purpose of preparing soap specifications that would give material of suitable quality to cover the general needs of the Government service and at the same time conform to commercial practice. The soap section of the American Specialty Manufacturers' Association appointed a technical committee, said to directly represent more than 90 per cent of the soap manufacturers of the 
country, to confer with the Government committee. As a result of this conference specifications were prepared by the two technical committees and submitted to the Federal Specifications Board and by it adopted as Government standards.

The methods of sampling and analysis given in the various soap specifications referred to and in this circular are those recommended by the Soap and Soap Products Committee of the American Chemical Society and were prepared by this committee in cooperation with the two technical committees mentioned above.

The following Federal specifications for detergent materials, issued by the Federal Specifications Board, have been published as circulars of the Bureau of Standards:

Federal specification on soap and related materials

\begin{tabular}{|c|c|c|}
\hline No. & Subject & $\begin{array}{l}\text { Publica- } \\
\text { tion (see } \\
\text { B. S. Cir. } \\
\text { No.) }\end{array}$ \\
\hline 26 & White floating soap (for toilet uss) & 1123 \\
\hline 27 & Liquid soap (for toilet use) & 124 \\
\hline 28 & Soap powder & 125 \\
\hline 29 & $\begin{array}{l}\text { Salt-water soap } \\
\text { Automobile soap }\end{array}$ & 126 \\
\hline 31 & Chip soap & 128 \\
\hline 32 & Ordinary laundry soap.... & 129 \\
\hline $33-\mathrm{a}$ & Grit-cake soap (a) and (b) & 130 \\
\hline $34-\mathrm{a}$ & Scouring powders for floors (a), (b), and (c). & 370 \\
\hline 35 & Hand grit soap. & 132 \\
\hline 246 & Liquid soap (for laundry use) ................ & 193 \\
\hline 244 & Milled toilet soap & 194 \\
\hline 245 & Pow dered soap (for laundry use) & 195 \\
\hline 429 & Soda ash. & 314 \\
\hline 430 & Caustic soda (lye). (For cleaning purposes). & 315 \\
\hline 431 & Laundry soda (washing soda) & 316 \\
\hline 432 & Granular sodium carbonate (monohydrate crystals) & 317 \\
\hline 558 & Technical trisodium phosphate (phosphate cleaner) & 369 \\
\hline
\end{tabular}

1 Numbers refer to circulars current January, 1930. These specifications will be reissued under the F. S. No. alone.

The following specifications have been issued by the Federal Specifications Board, but have not been published by the Bureau of Standards:

Federal specification No.:

340 for polishing paste.

341 for liquid metal polish.

390 for silver polish.

551 for laundry appliances.

The Bureau of Standards has prepared in cooperation with the manufacturers a recommended specification or so-called powdered ammonia. This has been issued as Bureau of Standards Letter Circular No. 124.

A specification for dry-cleaning solvent ("Stoddard solvent") has been prepared by the Bureau of Standards in cooperation with the National Association o Dyers and Cleaners of the United States and Canada, and with the petroleum producers and refiners. This specification has been published as Bureau of Standards Commercial Standard No. CS3-28. 


\section{APPENDIXES}

The following appendixes give proposed specifications for special grade laundry soap and hard-water laundry soap. They were submitted by the manufacturer's' committee and represent soaps which have very extensive commercial use and are believed to be satisfactory for the grades of soap indicated. These specifications have not been recommended for adoption as Government standards, as there appears to be no demand at this time for soaps of this kind in the Government service.

\section{Appendix 1. PROPOSED SPECIFICATION FOR SPECIAL GRADE LAUNDRY SOAP}

\section{GENERAL}

The soap desired under this specification is a high-grade, wellmade, uniformly mixed laundry soap, made from soda and fats, free from or with only a relatively small proportion of rosin, low in matter insoluble in alcohol, free from objectionable odor, and suitable for use with soft water for general cleaning and laundry purposes. Bidder shall state size, weight, and number of cakes in each box.

Failure to meet any of the following requirements will be cause for rejection:

Matter volatile at $105^{\circ} \mathrm{C}$. shall not exceed 34 per cent. Deliveries which yield more than 34 per cent of volatile matter will be rejected without further test.

The sum of free alkali, total matter insoluble in alcohol, and sodium chloride shall not exceed 5 per cent.

Free alkali, calculated as sodium hydroxide $(\mathrm{NaOH})$, shall not exceed 0.2 per cent.

Matter insoluble in water shall not exceed 1 per cent.

Rosin shall not exceed 20 per cent.

The percentage of matter volatile at $105^{\circ} \mathrm{C}$. will be computed on the basis of the soap as received, but all other constituents will be calculated on the basis of material containing 30 per cent of matter volatile at $105^{\circ} \mathrm{C}$.

The material will be purchased by net weight, provided the matter volatile at $105^{\circ} \mathrm{C}$. does not exceed 30 per cent. With deliveries containing more than 30 per cent, but not exceeding 34 per cent of matter volatile at $105^{\circ} \mathrm{C}$., settlement will be made on the basis of 30 per cent of matter volatile at $105^{\circ} \mathrm{C}$; that is, seven-tenths of a pound of nonvolatile matter shall be considered 1 pound of soap.

Examples: (1) Yield 28 per cent of matter volatile at $105^{\circ} \mathrm{C}$., pay for net weight.

(2) Yield 33 per cent of matter volatile at $105^{\circ} \mathrm{C}$., percentage of net weight to be paid for is calculated as follows: $(100-33) \times 10 / 7=$ 95.71 per cent.

\section{SAMPLING}

One cake shall be taken at random from not less than 1 per cent of the seller's shipping containers, provided such containers contain not less than 50 pounds each. In the case of smaller containers a cake shall be taken at random from each lot of containers totaling not to exceed 5,000 pounds. The total sample shall in all cases consist of not less than three cakes taken at random from separate 
containers. With very large lots, where the sample drawn as above will amount to more than 20 pounds, the percentage of packages sampled shall be reduced so that the amount drawn shall not exceed 20 pounds.

Wrap the individual cakes tightly in paraffined paper at once and seal by rubbing the edges with a heated iron. The inspector should accurately weigh each wrapped cake, record its weight and the date of weighing on the wrapper, place the wrapped cakes in an air-tight container, which should be nearly filled, seal, mark, and send to the laboratory for test. Samples should be kept cool until tested. The seller shall have the option of being represented at the time of sampling and, when he so requests, shall be furnished with a duplicate sample.

\section{LABORATORY EXAMINATION}

(a) Preparation of Sample.-In case of samples that can be easily disintegrated and mixed, run the entire sample through a suitable chopper. When the sample is large, each cake may be quartered and one-quarter of each cake run through the chopper. With samples that can not be handled as above, select a cake of average weight, quarter by cutting at right angles in the center, and shave equally from all freshly cut surfaces sufficient soap for analysis. Mix and weigh out all portions for analysis promptly. Preserve the remainder in an air-tight container in a cool place. When a determination shows nonconformity with specification, a duplicate shall be run.

(b) Matter Volatile at $105^{\circ}$ C.-Weigh $5 \mathrm{~g}$ of the sample in a porcelain or glass dish about 6 to $7 \mathrm{~cm}$ in diameter and $4 \mathrm{~cm}$ deep, dry to constant weight in an inert atmosphere at a temperature not exceeding $105^{\circ} \mathrm{C} .^{8}$ Report loss in weight as matter volatile at $105^{\circ} \mathrm{C}$.

(c) Total Matter Insoluble in Alcohol, Free Alkali, or Free ACID.-(1) Matter insoluble in alcohol.-Digest hot a $10 \mathrm{~g}$ sample with $200 \mathrm{ml}$ of freshly boiled neutral ethyl alcohol (94 per cent or higher). Filter through a counterpoised filter paper, neutral to phenolphthalein, or a weighed Gooch crucible with suction, protecting the solution during the operation from carbon dioxide and other acids. Wash the residue on the paper or in the crucible with hot, neutral alcolol until free from soap. Dry the filter paper or crucible and residue at $100^{\circ}$ to $105^{\circ} \mathrm{C}$. for three hours, cool, and weigh the total matter insoluble in alcohol.

(2) Free alkali or free acid.-Titrate the filtrate from $3 c$ (1), using phenolphthalein as indicator, with standard acid or alkali solution and calculate the alkalinity to sodium hydroxide or acidity to oleic acid.

(3) Matter insoluble in water.--Proceed as in the determination of matter insoluble in alcohol. After filtering and thoroughly washing the residue extract it with water at $60^{\circ} \mathrm{C}$. and wash the filter thoroughly. (When the matter insoluble in water is all inorganic, boiling: water may be used for the extraction and washing.) Dry the filter and residue at $100^{\circ}$ to $105^{\circ} \mathrm{C}$. for three hours, cool, and weigh matter insoluble in water. The nature of this may be determined by further examination.

s Time can be saved by having a layer of about $3 \mathrm{~mm}$ of ignited sand and a small stirring rod weighed with the dish and dissolving the sample in absolute alcohol, evaporating to dryness, breaking up the sample with the rod, adding more alcohol, again evaporating, and completing the drying in the oven as above. 
(d) Chloride. ${ }^{9}$-Dissolve $5 \mathrm{~g}$ of the sample in $300 \mathrm{ml}$ of water, boiling, if necessary, to dissolve all soluble matter. Add an excess of neutral, chlorine-free magnesium nitrate solution (about $25 \mathrm{ml}$ of a 20 per cent solution of $\left.\mathrm{Mg}\left(\mathrm{NO}_{3}\right)_{2} \cdot 6 \mathrm{H}_{2} \mathrm{O}\right)$. Without cooling or filtering titrate with standard silver nitrate solution, using potassium chromate as indicator. Calculate the chloride as sodium chloride.

(e) Rosin.-Wolff's method. ${ }^{10}$ Dissolve $5 \mathrm{~g}$ of the sample in 100 to $200 \mathrm{ml}$ of hot water, add a slight excess of dilute sulphuric acid, heat until the fatty acids collect in a clear layer, cool to room temperature, extract with a small portion of ether, draw off the water layer, and wash the ether solution with water until free from mineral acid. Transfer to a $200 \mathrm{ml}$ Erlenmeyer fiask, evaporate off the ether and dry for one hour at $105^{\circ} \mathrm{C}$, cool, and dissolve in $20 \mathrm{ml}$ of absolute alcohol. Then add $10 \mathrm{ml}$ of a solution of 1 volume of concentrated sulphuric acid (specific gravity 1.84) and 4 volumes of absolute alcohol and boil for four minutes under a refiux condenser. Remove from steam bath and add to the liquid about five times its volume of a 7 to 10 per cent solution of sodium chloride and extract with ether. Shake out the aqueous portion two or three times with ether. Unite the ether solutions and wash with sodium chloride solution until the washings are neutral to methyl-orange. Add $30 \mathrm{ml}$ of neutral alcohol and titrate the rosin acias with standard sodium hydroxide solution, using phenolphthalein as indicator. Calculate to rosin or rosin soap, as desired ( $1 \mathrm{ml}$ normal alkali $=0.346 \mathrm{~g}$ rosin or $0.377 \mathrm{~g}$ rosin soda soap).

\section{REAGENTS}

(a) Standard Sodium Hydroxide Solution.-0.25 $\mathrm{N}$, or about $10 \mathrm{~g}$ of sodium hydroxide dissolved in water and diluted to 1 liter. Standardize against Bureau of Standards standard acid potassium phthalate.

(b) Standard Sulphuric Acid Solution.-0.5 $\mathrm{N}$, or about 25.8 $\mathrm{g}$ of concentrated sulphuric acid (specific gravity $=1.84$ ) diluted to 1 liter. Standardize against standard sodium hydroxide solution (a).

(c) Standard Silver Nitrate Solution.-0.10 N, or about $17 \mathrm{~g}$ of silver nitrate dissolved in water and diluted to 1 liter. Standardize against pure sodium chloride.

(d) Potassium Chromate Solution.-A 10 per cent solution of potassium chromate $\left(\mathrm{K}_{2} \mathrm{CrO}_{4}\right)$ in water.

\section{Appendix 2. PROPOSED SPECIFICATION FOR HARD-WATER GRADE LAUNDRY SOAP}

1. GEINERAL

The soap desired under this specification is a well-made uniformly mixed laundry soap, made from soda and fats, of which not less than 20 per cent shall be coconut oil; free from rosin, free from objectionable odor and suitable for use with hard water for general cleaning and laundry purposes. Bidder shall state size, weight, and number of cakes in each box.

Failure to meet any of the following requirements will be cause for rejection:

H. C. Bennett, J. Ind. Eng. Chem., 13, p. 813: 1921.

10 Chem.-Ztg., 38, pp. 369-370, 382-383, 430; Chem. Abst. 8, p. 2495; 1914. 
Color to match that of sample submitted for color only.

Matter volatile at $105^{\circ} \mathrm{C}$. shall not exceed 44 per cent.

Deliveries which yield more than 44 per cent of volatile matter will be rejected without further test.

The sum of free alkali, total matter insoluble in alcohol, and sodium chloride shall be not less than 8 per cent nor more than 20 per cent.

Free alkali, calculated as sodium hydroxide $(\mathrm{NaOH})$, shall not exceed 0.5 per cent.

Matter insoluble in water shall not exceed 1.0 per cent.

The acid number of the mixed fatty acids prepared from the soap shall be not less than 205 .

The percentage of matter volatile at $105^{\circ} \mathrm{C}$. will be computed on the basis of the soap as received, but all other constituents will be calculated on the basis of material containing 38 per cent of matter volatile at $105^{\circ} \mathrm{C}$.

The material will be purchased by net weight, provided the matter volatile at $105^{\circ} \mathrm{C}$. does not exceed 40 per cent. With deliveries containing more than 40 per cent, but not exceeding 44 per cent of matter volatile at $105^{\circ} \mathrm{C}$., settlement will be made on the basis of 40 per cent of matter volatile at $105^{\circ} \mathrm{C}$.; that is, six-tenths of a pound of nonvolatile matter shall be considered 1 pound of soap.

Examples.-(1) Yield 39 per cent of matter volatile at $105^{\circ} \mathrm{C}$, pay for net weight.

(2) Yield 42 per cent of matter volatile at $105^{\circ} \mathrm{C}$, , percentage of net weight to be paid for is calculated as follows: $(100-42) \times 10 / 6=$ 96.67 per cent.

\section{SAMPLING}

Follow procedure given in section 2, Appendix 1.

\section{LABORATORY EXAMINATION}

Preparation of sample, matter volatile at $105^{\circ}$ C., total matter insoluble in alcohol, free alkali or free acid, matter insoluble in water, and chloride: Follow procedures $(a),(b),(c)$, and $(d)$ in section 3 of Appendix 1.

(e) Acid Number.-(1) Preparation of fatty acids.-Dissolve about $50 \mathrm{~g}$ of the soap in $300 \mathrm{ml}$ of hot water, transfer to a separatory funnel, add $150 \mathrm{ml}$ of approximately $2 \mathrm{~N} \mathrm{H}_{2} \mathrm{SO}_{4}$, cool somewhat, add $120 \mathrm{ml}$ of ether, shake, draw off the acid layer, and wash the ether layer free from mineral acid with a strong salt $(\mathrm{NaCl})$ solution. Then draw off the aqueous layer as completely as possible, transfer the ether layer to a flask (it is not necessary to transfer quantitatively), add 20 to $30 \mathrm{~g}$ of anhydrous sodium sulphate $\left(\mathrm{Na}_{2} \mathrm{SO}_{4}\right)$, stopper the flask, shake and let stand at a temperature below $25^{\circ} \mathrm{C}$. until the ethereal liquid becomes perfectly clear, showing that all water has been taken up by the sodium sulphate. Filter through a dry paper into another Erlenmeyer flask and completely evaporate off the ether by passing through the flask a current of dry air while heating the flask to a temperature not above $50^{\circ} \mathrm{C}$.

(2) Determination.-In a $250 \mathrm{ml}$ Erlenmeyer flask dissolve about $2 \mathrm{~g}$ of the fatty acids, accurately weighed, in 20 to $30 \mathrm{ml}$ of neutral 95 per cent ethyl alcohol. Titrate with a standard alkali, using phenolphthalein as indicator. Calculate the acid number ( $\mathrm{mg}$ of $\mathrm{KOH}$ per $g$ of fatty acids). 
$(f)$ Rosin.-A qualitative test for rosin may be made as follows: After decomposing a solution of the soap and separating the fatty acids, heat a small quantity of the latter with acetic anhydride, cool, place a few drops on a spot plate and add a drop of $\mathrm{H}_{2} \mathrm{SO}_{4}$ (specific gravity 1.53). A fugitive violet color indicates the presence of rosin.

\section{REAGENTS}

Standard sodium hydroxide solution, standard sulphuric acid solution, standard silver nitrate solution and potassium chromate solution: See $(a),(b),(c)$, and $(d)$ under section 4 of Appendix 1.

(e) Sulphuric Acid (specific gravity 1.53).-Mix $62.5 \mathrm{ml}$ of strong sulphuric acid (specific gravity 1.84 ) with $61.5 \mathrm{ml}$ of water.

$(f)$ Standard Alcoholic Sodium Hrdroxide Solution.-Same as (a), excepting that ethyl alcohol (94 per cent or higher) is used instead of water.

Washington, January 10, 1930. 
